\title{
Incorporating local institutions in irrigation experiments: evidence from rural communities in Pakistan
}

\author{
Aneeque Javaid $^{1,2}$ and Thomas Falk ${ }^{3}$
}

\begin{abstract}
Many irrigation systems are special cases of common-pool resources (CPRs) in which some users have preferential access to the resource, which in theory aggravates collective action challenges such as the under-provision of necessary infrastructure as a result of unequal appropriation of water resources. We present experimental evidence based on an irrigation game played in communities that are dependent on one of the largest contiguous irrigation network: the Indus basin irrigation system in Punjab, Pakistan. Furthermore, we simulate two institutional mechanisms that are neglected in experimental studies, despite their importance in many CPR governance systems: traditional authorities and legal pluralism. In our experiments, Punjabi farmers $(N=160)$ managed to provide the CPR at a level close to the social optimum, even without communication or enforcement opportunities. The equal investment in water infrastructure seems to be a strong social norm, even though those in disadvantageous positions (tail-users) earn less than those who have preferential access (head-users). At the same time, head-users restrain themselves from maximum resource extraction, which could be interpreted either as a norm or a stationary bandit strategy. In contrast to one of the most consistent findings of previous experimental studies, the participants in our experiment increased their earnings over the experimental rounds by using the available resources in a more efficient manner. One explanation for this behavior could be the availability of social information in our game. Starting from a high level of cooperation during baseline rounds, the treatments did not change the group investment significantly. The introduction of external sanctions created additional coordination problems, which led to a decrease in the level of group welfare. More specifically, head-users reduced their water extraction in the face of possible external sanctions to a level that the remaining water could not be used completely by tail-users.
\end{abstract}

Key Words: asymmetric access; common-pool resources; field experiments; irrigation management; Punjab, Pakistan; traditional authorities

\section{INTRODUCTION}

Many irrigation systems, especially in developing countries, show characteristics of common pool resources (CPRs) and are managed as common property. Often, a group jointly maintains infrastructure such that the investment of an individual generates positive externalities for the whole group. Standard economic theory predicts that this leads to free-riding behavior and, consequently, under-investment in resource provision (Olson 2009). In addition, participants in irrigation systems have to be aware of the negative externality caused by an individual user's water extraction, which reduces the amount available for others (Gordon 1954, Scott 1955, Hardin 1968). Irrigation systems also represent a somewhat unique problem of asymmetric (preferential) access to the resource for some users, which exacerbates the challenges associated with provision and extraction problems (Ostrom and Gardner 1993).

In theory, different institutional mechanisms can solve cooperation challenges in irrigation management. Proponents of state regulations argue that effective development and management of irrigation systems only works under a central authority (Wittfogel 1981). In contrast, proponents of market solutions argue that market coordination on the basis of welldefined property rights can provide incentives for welfare maximizing infrastructure investments and extraction (Deininger and Feder 2009). Both of these perspectives implicitly assume that communities sharing these resources do not have the incentives or capacity to cooperate and effectively manage CPRs. In contrast to this assumption, a large number of case studies in both developed and developing countries show that many communities have been relatively successful in managing CPRs with asymmetric access (Fleuret 1985, Coward and Levine 1987, Hunt 1988, Tang 1992, Bardhan 2000, Sarker and Itoh 2001, Trawick 2001).

Experimental studies, by observing human behavior in controlled settings, have directly challenged the theoretical basis of these simple solutions. For instance, a common finding in public-good games is that participants generally invest $50-70 \%$ of their endowment in the provision of a given public good (Ledyard 1994). This conflicts with rational choice theory, which predicts short-sighted selfish behavior.

Our study adds to this discussion by incorporating the asymmetric access problem, which is a special feature of irrigation systems, with the use of a standard CPR game. We wanted to learn how communities with a long history of irrigation management respond to the interconnected challenges associated with the provision and extraction of a CPR in the face of asymmetric access. For this purpose, we examined experimental evidence from an old and one of the largest irrigation systems, namely the Indus basin irrigation system in Punjab, Pakistan. Irrigation infrastructure has historical significance in this area, which is underlined by the fact that most of the modern settlement in the area resulted from the extension of irrigation systems to provide consistent year-round water supply to the settlers. To the best of our knowledge, we carried out one of the first social dilemma experiments in Pakistan, and as a result, we hope that this study will enable contextualized knowledge about the management of this crucial CPR. 
We had two overarching research questions: (1) At what level do Punjabi farmers manage to provide to and extract from an irrigation-related CPR? (2) How do Punjabi farmers respond to different governance interventions experienced by the communities in the past? The history of Punjabi irrigation management is marked by repeated shifts in the governance system. Customary practices were replaced by statutory regulations, and democratic principles were externally introduced to the communities. We simulated major steps in the history of Punjabi irrigation governance in our experiments in a very simplified way and assessed how farmers react to these interventions. We were especially interested in two institutional mechanisms, which, despite their importance in many governance systems world-wide, are often neglected in experimental studies: traditional authorities and legal pluralism.

We attempted to answer our research questions using artefactual field experiments (Harrison and List 2004). Our experimental design was based on that of Janssen et al. (2011b), which incorporates the challenge of asymmetric access. We extended the game by providing social information in terms of revealing the players' decisions throughout the game.

Our results suggest that participants were able to generate solutions that are substantially better than the predictions of standard economic theory. Also, contrary to other experimental studies, participants in our experiment were able to increase their earnings with the passage of time. However, introducing institutions had a relatively small effect on group welfare. Institutions were more important in appropriation aspects of the CPR dilemma. External sanctions, although successful in deterring head-users from overextraction, created coordination problems, which led to inefficient outcomes for the group as a whole.

The paper is organized as follows. We first provide background information about the study site, as well as the history and development of the Indus basin irrigation system. We then discuss the experimental design. Next, we give a brief overview of the theoretical foundations of the problem and the possible outcomes. Finally, we examine the most important results and placing them into the case context.

\section{FIELD SITE AND BACKGROUND INFORMATION}

Research was carried out in Sargodha district in the Punjab region of Pakistan (Fig. 1). Agriculture remains an integral part of Pakistan's society and economy, accounting for approximately $25 \%$ of the gross domestic product (World Bank 2005). Punjab is a mostly arid or semi-arid area and requires constant water supply for wheat, rice, and sugarcane production to be viable (World Bank 2004).

Punjab has an old and one of the most extensive irrigation systems in the world, the Indus basin irrigation system. Development of irrigation infrastructure in the area could be divided into three periods; pre-British rule, British rule, and post-independence. The Indus basin region was home to one of the earliest urban civilizations, which was renowned for its innovations in water management (Wheeler 1968, Possehl 2002). For millennia, annual floods of the Indus and its tributaries shaped the development of agriculture in the region (Gilmartin 1994). During the Mughal rule, inundation canals were constructed to open the areas that were distant from the direct action of river floods (Badruddin 1993). Construction of these inundation canals took place over a long period of time and required substantial labor for canal digging, as well as maintenance operations such as silt clearance (Gilmartin 1994). However, the water supply from these inundation canals was highly variable because inflows came mainly from seasonal snow, glacier melt, and infrequent rainfall.

Fig. 1. Location of the study. (A) Location of Punjab in Pakistan. (B) Location of Sargodha district in Punjab. Source: Government of Sargodha.

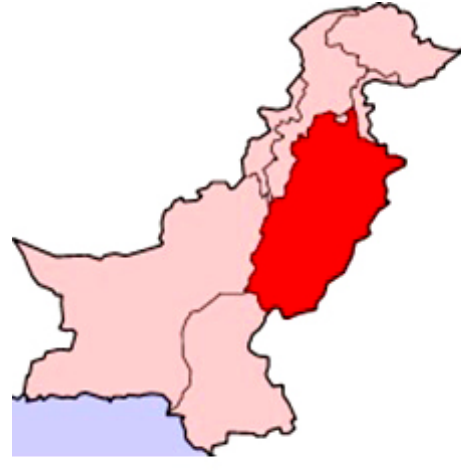

(A)

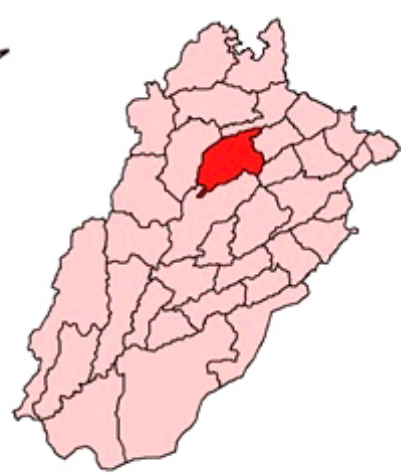

(B)
Starting from 1849, British rule marked the onset of construction of massive irrigation infrastructure. Initially, British planners only sought to expand and maintain existing inundation canal networks. However, they became increasingly more ambitious, building series of perennial, all-season canals to extend the irrigation system to far-off areas (Gilmartin 1994). Major canal construction was done in phases between 1861 and the mid-1930s (Ali 1987, 1988).

After independence in 1947, the government continued implementing the strategy originally laid out by the British (see Wescoat et al. 2000 for more details). By 1962, all traditional canals were integrated into a centralized system (Badruddin 1993). As a result of these developments, Pakistan has one of the largest integrated irrigation systems in the world, covering approximately 20.8 million ha (World Bank 2005). Approximately $90 \%$ of the country's agricultural output is produced in these areas (World Bank 2005).

The district of Sargodha is situated in the central-western plains of the Punjab between the Jhelum and Chenab rivers. It was part of one of the original "canal colonies", the Lower Jhelum Canal Colony scheme (Cheema at al. 2009). Canal colonies were largescale canal irrigation schemes, launched in the early 1890 s to bring water to noncultivated land areas in western Punjab. The purpose of this scheme was to expand settled agriculture (Agnihotri 1996). Extension of irrigation networks was accompanied by large-scale internal migration from the farming communities of the eastern Punjab (Cheema et al. 2009).

Indus basin irrigation system management in historical context The Indus basin irrigation system carries water from rivers to main canals (primary level) using barrages. This water flows into 
distributaries (secondary level) and through ungated concrete outlets (mogha) into watercourses (tertiary level). From here, it reaches the farmers' ditches and their fields (Merrey 1986a,b).

British planners designed the system to be managed centrally with the help of locally appointed officials. At the same time, it was intended to keep the tertiary level of management in the hands of local communities as much as politically and financially feasible. This reduced the infrastructure maintenance costs for the central authority. Labor required for maintenance operations was provided by the local users of canals, a system founded on both local formal and informal rules (de Klein and Wahaj 1998). The central management also reduced transaction costs of governance by deciding primarily on the distribution of water up to the tertiary canals. For tertiary-level extraction decisions, communities used informal rotation systems (Merrey 1986c).

During British rule, this combination of local and central governance was complemented by the strong inclusion and promotion of traditional authorities (panchayats). Panchayats formed, and still form, a crucial part of rural life in Punjab. They are composed of community elders and act as primary conflictresolution bodies. With regard to irrigation matters, they negotiate disagreements pertaining to the issues of canal maintenance and distribution of water between users. Even prior to colonial interference, panchayats played an important role in the management of irrigation systems. Nevertheless, they were given official recognition for the first time under the Punjab Village Panchayat Act of 1912 (Javid 2012). This act was reinforced in 1939, broadening the panchayats' sphere of influence considerably, which led to a proliferation of officially recognized panchayats (Javid 2012). As such, a typical policy of indirect rule was to implement traditional authorities who became extended arms of the central government (Mamdani 1996). The governance system effectively adopted a functioning informal institution and provided legal cover without too much official interference in its day-to-day operations.

In our study, we capture two distinct elements of traditional authority systems: (1) soft authority or leadership in which traditional authorities base their support on moral and social norms, rather than legal rules, and try to guide people in the direction of socially desirable behavior; and (2) informal sanctions, i.e., punitive action not involving monetary fines or imprisonment. For the most part, traditional authorities rely on informal sanctioning mechanisms such as social disapproval. Being taken to the panchayat is itself considered a deterrent because it induces serious damage to the reputation and social standing of the individual among the community at large. Denouncement or punishment (invariably nonmonetary informal sanctions) by the panchayat represents a serious warning for community members to mend their ways.

After Independence in 1947, many responsibilities were transferred from local communities and traditional authorities to the formalized local branches of the central bureaucracy. This was justified on the grounds of the increasing complexity of technological change and growing concerns of irrigation engineers about the efficacy of decentralized water management. Panchayats were written off from the laws, with their role effectively restricted to pre-1912 level, i.e., without any formal legal cover and based on local informal authority only. Starting in the 1970s, as a result of increasing conflicts among farmers and growing dissatisfaction with the influence of traditional local leaders, rules and regulations for provision of labor and extraction were gradually formalized (Merrey 1986c). We include this shift toward impersonalized external regulation of the irrigation system in our experiment by introducing an external punishment treatment.

In the late 1990s, the centralized management scheme gradually lost acceptance among local farmers. According to figures provided by the Irrigation Department, Government of Punjab, revenue collection from water taxes fell from $79 \%$ during the 1993 1994 season to $56 \%$ at the end of the 2000-2001 season. Irrigation infrastructure quickly deteriorated as farmers became more reluctant to provide labor for the maintenance work. In combination with escalating conflicts, this resulted in an uncoordinated and unfair distribution of water resources among farmers. There were complaints of overextraction by head-users and corruption of government officials (Bandaragoda and ur Rehman 1995). The Government of Punjab reacted by introducing a more participatory approach toward irrigation management in which the rights and duties regarding irrigation infrastructure were partially transferred to user organizations. An important element of this decentralization policy was the establishment of water-user associations, which received the responsibility to manage the irrigation system below the secondary canal level. This shift toward more participatory water governance is reflected in our experiment by a communication rule, enabling users to reach nonbinding agreements.

Development of the Indus basin irrigation system governance is, however, not a complete shift from one institutional mechanism to another. Instead, responsibility and authority moved between different organizations. Currently, irrigation system governance is rather a form of legal pluralism where state authorities, traditional authorities and democratically established community organizations coexist. Farmers can individually decide which organization to call upon. Their decision depends on which organization is perceived to be most suitable to solve a particular problem. We take this fact into account by introducing an institutional choice treatment in our experiment. Under this treatment, some experimental groups can choose between using formal impersonal punishment, traditional authorities, or communication to coordinate.

\section{EXPERIMENTAL DESIGN}

We replicate the irrigation system management challenges of Punjabi farmers in a very simplified manner by designing artefactual field experiments based on Cardenas et al. (2008), largely following the experiment design of Janssen et al. (2011b). Cardenas et al. (2008) outlined the "Irrigation Game", incorporating the most important elements of an irrigation system; namely the need to coordinate provision and asymmetric appropriation. These experiments were performed in two phases: without (baseline) and with institutional interventions (treatment phase).

Sargodha district comprises approximately 841 villages, of which 8 villages were chosen for experiments with the help of local agriculture extension staff. All participants were male and were directly associated with agriculture and irrigation. Most of the participants knew each other well, and sub-sections of participants in each village shared the same tertiary-level irrigation infrastructure. In each village, experiments were held at 
a place locally known as dera, a gathering place where community leaders and elders meet to discuss matters of general concern, including water disputes. People were invited to the experiments by Mosque loudspeaker announcements, cell phone messages, and word of mouth. Our invitation procedure was open to anyone from the community. Nevertheless, only males attended the sessions. This reflects the cultural reality in Punjab, where men dominate irrigation management. We summarized socioeconomic attributes of the sample population (Appendix 1) and sample (Table 1).

Table 1. Socioeconomic attributes of the sample population.

\begin{tabular}{lc}
\hline \hline Variable & Mean \pm SE or percentage \\
\hline Average age & $41 \pm 14.4 \mathrm{yr}$ \\
Average household size & $7.7 \pm 3.7$ people \\
Average size of landholdings & $13.0 \pm 15.0 \mathrm{acres}$ \\
Share of male & $100 \%$ \\
Received secondary education & $63 \%$ \\
Hold freehold land title & $85 \%$ \\
Own private tube well & $44 \%$ \\
\hline
\end{tabular}

In each village, participants were randomly divided into four different groups consisting of five members each. Each group was randomly assigned to one of four treatments: communication $(\mathrm{C})$, traditional authority (TA), punishment (P), or institutional choice (IC). Additionally, for the TA and IC treatment groups, an elder was present to act as the traditional authority. These elders, however, did not take provision or extraction decisions during the game. Each group received one of the four treatments. In total, 160 farmers played the game in 32 groups, and each treatment was applied to eight different groups. Sixteen elders were involved in the TA and IC treatments.

For each group, the baseline version was conducted first, and the treatments were introduced afterward. Participants were not aware of the treatment assigned to their group in the baseline phase. The baseline phase of the experiment always took seven rounds. The duration of the treatment phase varied randomly from eight to eleven rounds. Players were not aware of the number of rounds in each phase. We introduced this variation to avoid an end round effect and make backward induction more difficult. Because none of the players knew how long the game was going to last, this should not affect the theoretical predictions.

Within a group, each player was randomly assigned to a unique location ( 1 to 5 ). This position determined the sequencing of extraction decisions and remained fixed throughout the experiment. Players were aware of their position in the overall system.

At the start of each round, participants were provided with the same initial endowment of 10 tokens. During the baseline phase of the experiment, two decisions were repeated in every round. All participants first decided privately and simultaneously on the number of tokens each one wanted to invest in maintaining the irrigation infrastructure. Noncontributed tokens were kept in a private account.

The collective investment for a group was a simple additive function of all group members' individual investment, where each members' contribution carried the same weight. This feature of the experiment reflects the abiana (water tax) and labor contribution in the Pakistan irrigation management case.

After all of the group members decided on their abiana contribution, the total amount of common good produced was communicated to the group. The relationship between collective investment and the system's water flow capacity is determined by a sigmoidal production function similar to the one used by Janssen et al. (2011b; Fig. 2).

Fig. 2. Common-pool resource production function. Based on Janssen et al. (2011b).

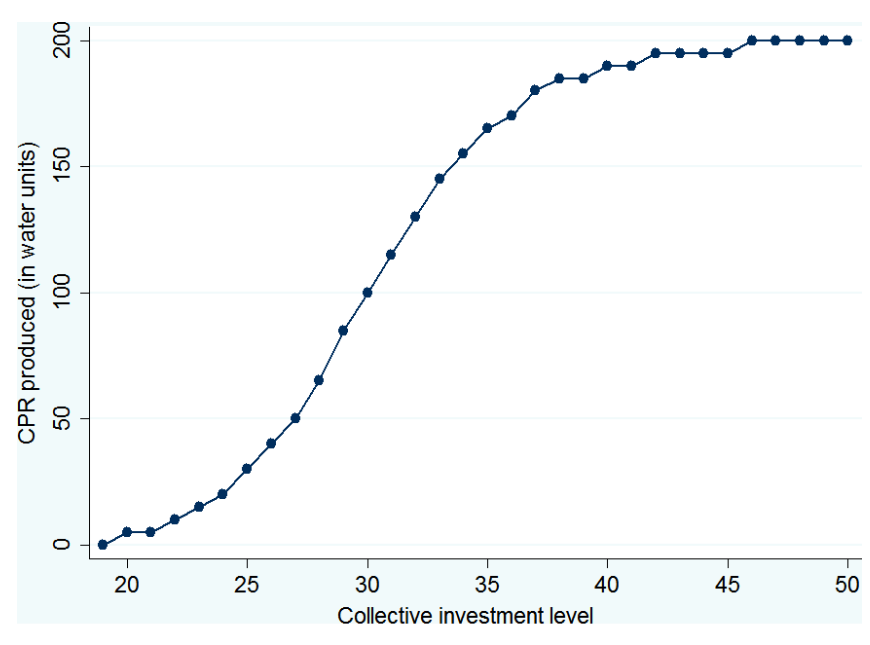

The advantage of using this function is that it captures the essential aspects of the Punjab irrigation systems. First, for low levels of overall contribution, very little water flow capacity is produced. Also, no single player is able to provide enough investment to maintain the infrastructure on his own, which is especially true of such large-scale irrigation systems. Moderate total contributions raise the produced amount of water flow capacity significantly. At higher levels of overall investment, the marginal productivity of additional investment units declines.

In the second decision of each experimental round, players decide about the amount of water extraction in the sequence of their assigned location. The extraction decision of the first mover imposes a negative externality on all other players because the amount of CPR available for subsequent players depends on this decision. The relationship between the amount of water extracted and tokens earned is also represented by an S-shaped function (Fig. 3) taken from Janssen et al. (2011b). Each player is informed how much water is left for him and how much water was extracted by players before him.

Total earnings for an individual in a round were determined by the amount of water used by this particular individual, plus the amount of initial endowment not invested. At the end of each round, total earnings and extractions of each player were announced publicly. This is a critical departure from the design of Janssen et al. (2011b) and affects the comparability with other studies based on this game as published, for instance in Janssen et al. (2012). 
Fig. 3. Pay-offs depending on water extraction decisions. Based on Janssen et al. (2011b).

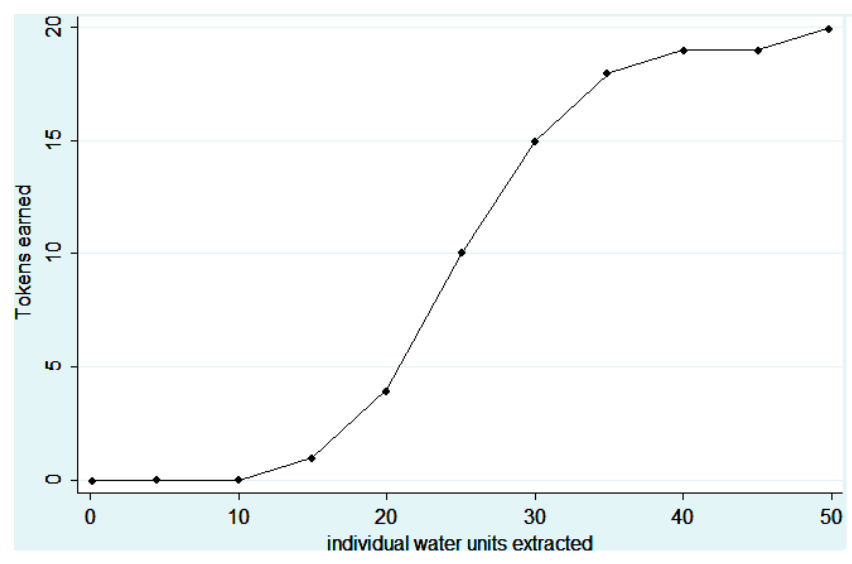

During the treatment rounds, players made three decisions. After making the provision and appropriation decisions as described for the baseline rounds, they could decide whether to initiate an institutional intervention against any particular player(s). Invoking a treatment is an individual decision and does not have to be agreed upon by the group.

We applied four types of treatments, each in different groups. The first treatment was face-to-face communication (C) in which players could directly talk to each other. Players could buy $2 \mathrm{~min}$ of time for cheap talk with fellow group members.

The second treatment was conflict resolution by traditional authorities (TA). During the treatment phase, elder(s) representing traditional authorities observed all the actions of the respective treatment group. Players could call upon the traditional leader to intervene. The traditional leader would conduct discussions with the relevant parties in the presence of all other players. Traditional leaders were provided with the same information as the actual players. All the actions and requests of the traditional leaders were nonbinding for the players.

The third treatment was external sanctioning or punishment $(\mathrm{P})$. In this treatment, players could point out a fellow player to be charged with a fixed fine of 4 tokens. If the punishment treatment is applied, there is a two-thirds probability that the inflicted player pays a fine of 4 tokens and a one-third probability that he pays nothing. This reflects the real-life transaction costs of monitoring and enforcement. Both the probability of receiving punishment, as well as the severity of punishment, are independent of the actions of the targeted player. The punishment treatment is not based on a rule with the explicit description of an expected behavior. It is rather based on norms of implicitly expected behavior.

In the case of the fourth treatment, institutional choice (IC), we imitated legal pluralism in a simple way. Players received explanations of the three aforementioned mechanisms: C, TA, and $\mathrm{P}$. In any round, they could individually choose whether to use any one of the three interventions. There was no need to make a collective choice in the group. This treatment was the most complex. We expected good understanding because the participants could connect all treatments to their real-life experiences. Furthermore, we only started the game after players managed to answer quiz questions correctly.

All treatments are costly for the individual invoking the treatment and do not provide any direct monetary benefit to the executing player. For C, a player could talk to any number of players in his group during the allocated $2 \mathrm{~min}$ at the cost of 1 token. For TA and $\mathrm{P}$, the cost of invoking the treatment against a single player was 1 token. This cost could be shared with other players if they also initiated the treatment against the same player in the same round. Each player could initiate these treatments against any number of players in a given round.

Participants were given USD \$0.65 as an attendance fee, with the possibility of earning more by participating in the experiment. Earnings in terms of tokens kept in the private account as well as tokens earned from CPR extraction were exchanged at the same rate into real money (USD $\$ 0.08$ per token). Experiments were designed to generate expected earnings equivalent to one day's salary of an unskilled worker. Participants were paid at the end of the game in a discrete manner. After the experiments, all participants were also invited to a lunch. In all cases, efforts were made to call local leaders and elders for the role of the traditional authority. However, in one case, this was impossible, and the eldest person was chosen to act as the leader. For a detailed description of the experimental procedure see Appendix 2.

\section{HYPOTHESIS AND THEORETICAL PREDICTIONS}

The scenario depicted in our experiment calls for the Nash equilibrium strategy of individual players to act in a selfish manner and in consideration of the short-run, i.e., not to invest anything in the CPR (keep the full endowment in their private account) and extract the maximum possible amount, resulting in a situation where no one invests in the common good and no resource is produced. In contrast, the maximum level of group earnings that could be achieved in our experiment design (104 tokens) requires that players collectively invest either 37 or 38 tokens, resulting in 180 or 185 units of water flow capacity, respectively. Producing an optimal amount of CPR does not mean that socially optimal equilibrium is achieved because this also requires efficient appropriation of water. So, for example, to attain maximum extraction earnings of 91 tokens at the collective investment level of 37 tokens, four players can extract 35 units of water (18 tokens for each player) while only one player can extract 40 units (19 tokens).

With respect to asymmetric access, we are aware of the following two relevant theoretical frameworks: those of Ostrom and Gardner (1993), and Singleton and Taylor (1992) and Olson (1993). The Ostrom and Gardner (1993) model is based on the concept of marginal utility of investment. It predicts that (1) due to the presence of asymmetric access, head-users extract more compared to tail-users; and (2) because of this difference in extraction, head-users will be expected to bear a greater share of investments in the provision and maintenance of the irrigation infrastructure.

Singleton and Taylor's (1992) concept of cooperation through "mutual vulnerability" and Olson's (1993) stationary bandit hypothesis as applied in Janssen et al. (2011a) follow the logic that 
communities can endogenously achieve cooperation due to the presence of mutually vulnerable actors. Singleton and Taylor (1992:315) define mutual vulnerability as "the condition of a group of actors each of whom values something which can be contributed or withheld by others in the group and can therefore be used as a sanction against that actor." In the case of Punjab water distribution, any farmer can contribute or withhold his participation in the cooperative infrastructure maintenance. Because no user can build or maintain irrigation infrastructure on his own, the withholding of cooperation is a credible threat and can be used as a sanction. Consequently, we would expect that (1) head-users have incentives to maintain cooperation within the group and not to extract exceedingly high amounts of water, and (2) tail-users maintain their investment levels in CPR provision as long as they receive their perceived fair share.

We adapted the experimental design of Janssen et al. (2011b) and provided direct individual feedback on extraction levels to increase the external validity of our experiments. Irrigation farming communities in Pakistan are marked by a low degree of privacy. In particular, water management activities are difficult to keep secret from fellow farmers. In addition, our treatments required individual social information in terms of revealing the players' water extraction. We revealed the extraction amount in the baseline rounds as well to avoid mixing the effect of institutional treatments with the social information effect. As such, it was not our objective to assess the effect of social information on the behavior of participants. However, we expect different behavior than in similar games played without providing this information.

The transparency of individual extraction rates has two implications. Eacg player could learn about what other players did, and everyone would know how much water each player extracted.

People comply with social norms because they wish their actions to be approved. Social approval or disapproval does not have to be expressed explicitly. Often an actor's anticipation of approval or disapproval already constitutes significant benefits or costs for that actor. Playing a simple public good experiment, Rege and Telle (2004) found evidence that people increase their cooperation levels when their decisions are made public. Soetevent (2005) observed that under specific conditions, church donations increase when neighbors can see how much a person is donating. Panagopoulos (2010) carried out an experiment in which the names of either voters (pride treatment) or nonvoters (shame treatment) in public elections were published in local newspapers and found evidence that shame increased election turn-outs, whereas pride was effective only for sub-groups of society.

For this mechanism to work, however, it is necessary that the actor beholds a social norm as a belief on how others expect him to act. Such beliefs can be present as the result of lifelong teaching, socialization, imitation, or conditioning processes (Smith [1789] 2004, Coleman 1987, North 1990, Ostrom 2009). Social norms can also be influenced by observing the instantaneous behavior of others.

Croson and Shang (2008) assessed to what extent knowledge about other people's donor behavior influences an individual's donations. They found that people increase their contributions when they are told that another person gave more than their previous contribution, and decreased it when they were told another person gave less. The downward effect was significantly stronger than the upward effect. Learning about other people's behavior influences beliefs about social norms, which thereby influence one's own behavior (Croson and Shang 2008).

Mittone and Ploner (2011) distinguished the effects of being observed and knowing other players' behavior using a simple investment game. The players showed significantly higher degrees of reciprocity when being observed. The social spillover effect from learning about other people's choices was much weaker, although still significant.

Enforcement based on anticipated approval has high policy relevance. It has the great advantage of not causing considerable social costs (Rege and Telle 2004, Falk et al. 2012).

In summary, the transparency of individual extraction rates very likely makes people adjust their extractions to what they believe is approved by fellow players. Not extracting more than what is anticipated to be the fair rate is motivated by avoiding shame. Some players may strive for pride by extracting even less than what they believe is their fair share. In addition, we would expect that the observed extraction rates create expectations or social norms about the individual fair share. As such, the extractions within a group should become more equal over the rounds. An increase in extraction levels would be consistent with Croson and Shang's (2008) results and would confirm that the downward effect of social information is stronger than the upward effect.

All treatments are costly and do not yield any direct monetary benefit for the initiator. Therefore, theoretically, we should not expect any effect of these institutions (second-order public goods). Nevertheless, from experimental evidence, we know that, (1) participants provide this second-order public good even though doing so is costly (Ostrom 1990, Ostrom et al. 1992, Fehr and Gächter 2000), and (2) the level of cooperation is often maintained or even enhanced by the presence of opportunities to communicate (Ostrom et al. 1992, Sally 1995, Bicchieri 2002, Balliet 2010) or to sanction other players (Fehr and Gächter 2000, Gürerk et al. 2006, Nikiforakis and Normann 2008).

The willingness to apply costly sanctions can be explained by the concept of positive or negative intrinsic values such as joy or regret (Ostrom 2009). Sanctioning does not need to produce material revenues if it is based on the intrinsic belief in the rightness of an action (Smith 1759). Fehr and Gächter (2000) and Falk et al. (2005) also argue that the decision of participants to sanction each other is based on their motivation to harm those who are perceived as behaving unfairly.

Our P rule was not linked to the investment or extraction level, but a fixed amount of 4 tokens. It might be rational under this treatment not to invest and to maximize extraction. It is difficult to assess when it is rational to give up extra extraction as a result of threat of punishment because the probability of treatment is linked to the perceptions of other players and not to any objective criterion. Nevertheless, consider a situation in which a player can extract the maximum possible amount of water. If he extracts the maximum amount, he would receive 20 tokens compared to 18 tokens for the social optimal extraction. Under the P treatment, the player risks losing 4 tokens with two-thirds probability if 
punishment is initiated against him. Theoretically, a rational player would therefore extract the maximum amount of water if his expected probability to be punished is lower than threequarters. This is a realistic assumption taking into account that sanctions are costly and do not yield any direct monetary benefits for other players.

The TA treatment combines the attributes of (informal) sanctions as well as communication. Both the $\mathrm{C}$ and TA treatments give participants an opportunity to coordinate directly. Furthermore, they inhibit the possibility of using social enforcement mechanisms (see also Falk et al. 2012). Balliet (2010) emphasizes three explanations why communication supports cooperation: receiving signals about other's willingness to cooperate, group identity, and the development of shared norms. The $\mathrm{C}$ treatment only allows for application of horizontal social consequences, whereas under the TA rule, a vertical social sanctioning mechanism is added. Through a process of discussion guided by influential elders, TA induces focus on pro-social norms without compromising the opportunity to punish undesired behavior.

\section{RESULTS}

Baseline individual and group-level results

Average investments in the baseline phase were 7.30 tokens (SE $=2.37$ ), which is approximately $70 \%$ of the individual endowments. The average investment level remained stable throughout this phase ( $P=0.58$ for two-tailed t-test between $1 \mathrm{st}$ and 7 th rounds). Only $1.7 \%$ of observations conformed to the Nash strategy of zero contribution, whereas the maximum possible investment was the most frequently chosen strategy in approximately $25 \%$ of the observations. The average group investment was approximately 36.28 tokens $(\mathrm{SE}=6.99)$ and remained stable throughout the baseline rounds $(P=0.69$ for twotailed t-test between 1 st and 7 th rounds). The average investment was very close to the social optimal CPR provision level, which is 37 tokens. In none of the rounds did group investment fall to zero.

The average individual extraction level during the baseline phase was 30.21 water units $(\mathrm{SE}=15.55)$. It was stable over the rounds ( $P=0.72$ for two-tailed t-test between 1 st and 7 th rounds). Players extracted the maximum amount of water in only $14 \%$ of cases. Individual-level average earnings for the baseline rounds was 15.40 tokens $(\mathrm{SE}=7.40)$. Players earned nothing in only $1.79 \%$ of observations, whereas player earnings were $>10$ tokens in approximately $70 \%$ of the observations (Nash equilibrium). Average group earnings for the baseline rounds was 77.01 tokens $(\mathrm{SE}=22)$, which is $74 \%$ of the social optimum and $154 \%$ of the Nash equilibrium (Fig. 4).

All group members, independent of their position, showed very similar overall average investment levels (Fig. 5). Players in all positions invested, on average, approximately 7 tokens.

Contrary to investment levels, the average extraction levels depended on access to the resource. Wilcoxon matched-pairs signed-ranks tests showed that only the comparisons between players 1 and 2 as well as between players 3 and 4 showed no significant differences (Appendix 3, Table A3.2). For all other pairs, the preferentially positioned player appropriated significantly more. Tail-users accounted for approximately $60 \%$ of zero extraction cases, whereas head-users accounted for nearly $60 \%$ of the maximum extraction cases.
Fig. 4. Group earnings as a function of group investment in the baseline phase. Total number of observations $=$ total number of groups $\times$ number of baseline rounds $=32 \times 7=224$.

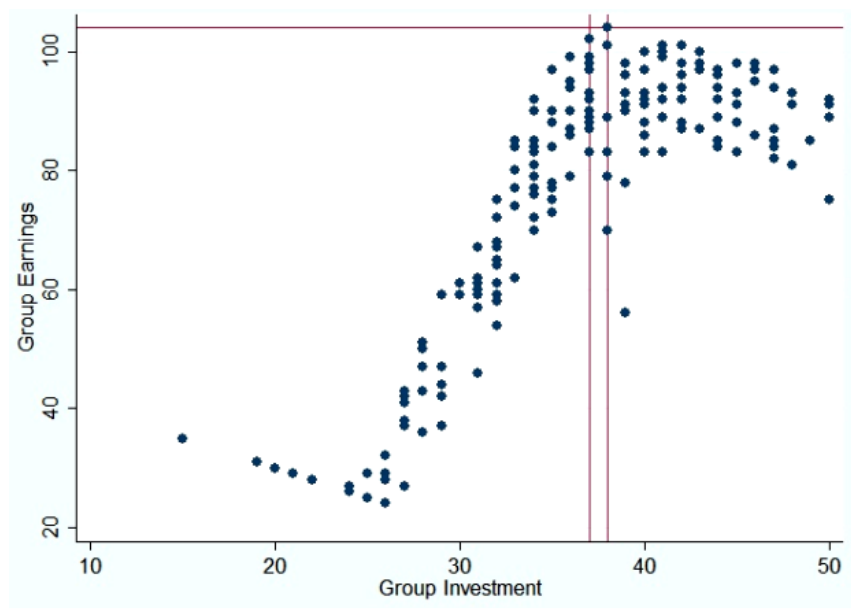

Fig. 5. Average investments, appropriations, and earnings during the baseline phase by player position.
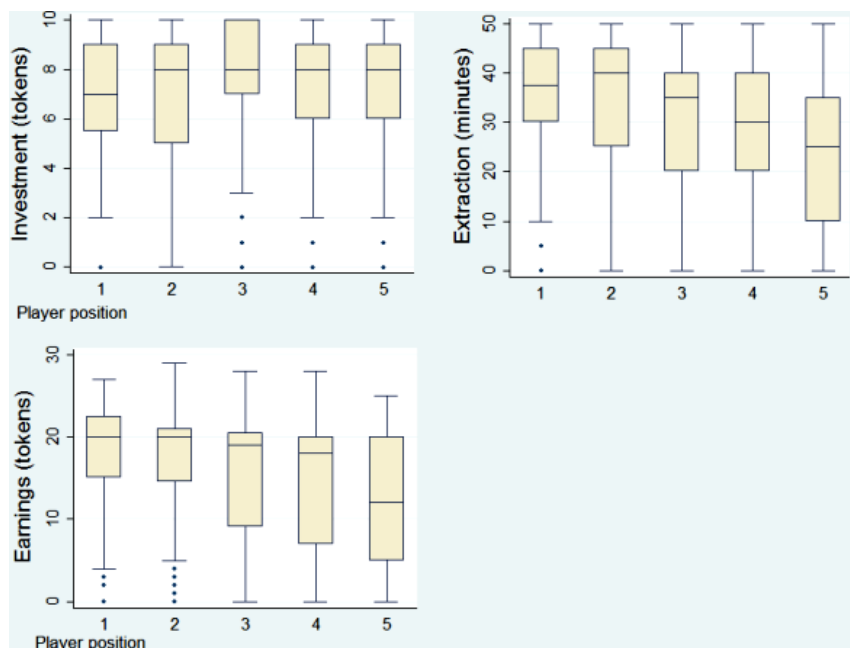

Player position

We further observe that the CPR appropriation was more unequal for lower levels of CPR and became increasingly equitable as the amount of CPR produced increased (Appendix 3, Fig. A.3.1). This provided incentives, especially for tail-users, to over-invest in the provision of CPR (greater than the socially optimum level).

\section{Introduction of institutions}

For the effect of the introduction of treatments on players' investments and earning levels, all reported earnings are gross earnings, which means that they do not include costs of treatment or fines that a player had to pay. Treatments could affect the behavior of participants in two possible ways. First, introducing treatments adds another phase to the game, which means that participants adjust their behavior with regard to this change. It is not important whether the participants actually used the 
treatment or not; rather, the mere presence of a treatment is enough to cause behavioral change. We call this the overall effect of treatment. Second, treatments could also affect behavior if a player initiated a treatment against one of their group members or if a treatment was initiated against them. We call this the direct effect of treatment.

We observe that most of the treatments were initiated by the tailusers against the head-users. This is especially true in the case of $\mathrm{P}$, for which almost $75 \%$ of the treatments were initiated by the players occupying the last two positions (positions 4 and 5). In the case of $\mathrm{C}$, only $40 \%$ of the treatments were initiated by players occupying these positions. Most of the treatments were initiated at the start of the treatment phase. External punishment $(\mathrm{P})$ was used relatively more consistently over the rounds. We also observe that the chance of a treatment being initiated against a player increased with his extraction level. Nevertheless, in $>40 \%$ of cases when a treatment was initiated, it was given against a player who extracted less than the group average (Fig. 6). We calculated tobit models (Appendix 4, Table A4.5) to understand the treatment decision of participants. These models reinforce our findings from descriptive analysis and do not suggest any significant and robust effect of socioeconomic indicators on treatment decision.

Fig. 6. Frequency of different sanction treatments applied against a player and the extraction levels of the targeted players.

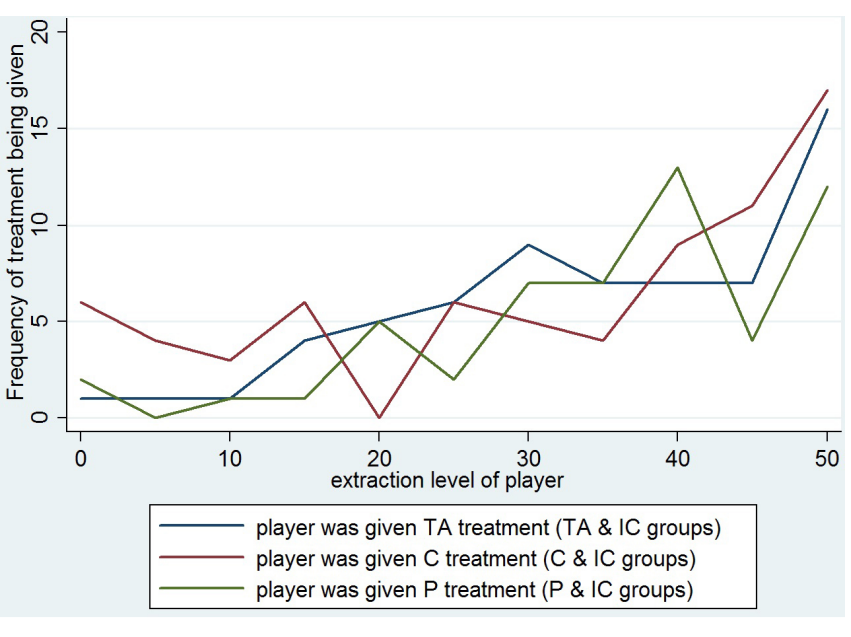

Tail-users had a higher probability to be given a treatment if they extracted less than the group average (comparison of means for position number by extraction below mean: $P=0.0025)$. This result should be seen in the light that any water reaching the 5 th player but not used by him did not provide benefits to anybody in the group and was considered wasted. Head-enders who restrained their water extraction felt sufficiently annoyed to punish water-wasting tail-users.

Although the figures for average investment and earning levels during the treatment rounds suggest higher provision and appropriation levels for the $\mathrm{C}$ and TA groups, Mann-Whitney tests provided no evidence for significant differences between the treatments (Fig. 7; Appendix 3, Table A3.3).
Fig. 7. Development of average provision and appropriation over game rounds depending on institutional setting.
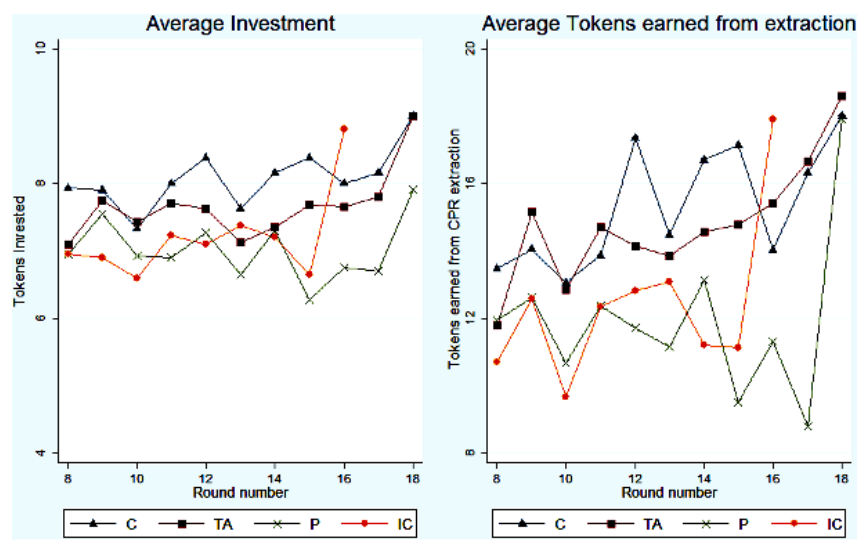

Taking into account the complexity of the experiment, we used multivariate, hierarchical, mixed-effects regression models (STATA 12) to analyze the players' decisions. This allowed us to control for variables on different scales. As such, we considered individual-context layer and group-context layer information. For individual-context layer information, we included three sets of variables: (1) socioeconomic indicators such as age, education level, and being a member of dominant kinship group; (2) farming related variables such as landholdings and access to private tube wells, which indicate the scale and sophistication of farming activities; and (3) individual attitudes and perceptions such as the level of trust and whether or not the player feels part of the community. Each set of variables could potentially affect the way participants interpret and respond to the dilemma presented in the experimental settings. The full models included these variables (Appendix 4); however, our results are similar even if we completely ignore the socioeconomic variables or include a different set of variables.

In regression models, the overall effect of treatments is captured by interaction terms between treatment groups and treatment phase $(\mathrm{C} \times$ treatment phase, $\mathrm{TA} \times$ treatment phase, $\mathrm{P} \times$ treatment phase, and IC $\times$ treatment phase); the interactions indicate the overall effect of the introduction of institutional treatments by comparing them to baseline rounds. In the baseline phase, these interaction terms are zero for all groups. In the treatment phase, these interaction terms are one for the specific treatment applied to a specific group, and zero for the treatments not applied to the specific group.

Treatments were initiated after the provision and appropriation decisions, so they could only directly affect the behavior in subsequent rounds. For a direct treatment effect, we examined the effect of both initiating and suffering from treatments in the previous round $(t-1)$. In the regression models, this is captured by six dummy variables (Initiated $C$ treatment $(t-1)$, Received $\mathrm{C}$ treatment $(t-1)$, and so on). These variables indicate whether a participant received or inflicted any treatment. For example, Initiated $C$ treatment $(t-1)$ is 0 if the participant did not inflict the $\mathrm{C}$ treatment on any other player, whereas it is 1 if the 
Table 2. Mixed-effects regression results of individual amounts invested and earned. Numbers are coefficients, with robust standard errors in parentheses.

\begin{tabular}{|c|c|c|c|}
\hline Variable level & Variable & $\begin{array}{c}\begin{array}{c}\text { Investment } \\
\text { (rounds 2-18) }\end{array} \\
\end{array}$ & $\begin{array}{c}\text { Earnings } \\
\text { (rounds 2-18) } \\
\end{array}$ \\
\hline \multirow[t]{7}{*}{ Individual level } & Education level & $-0.0857(0.0530)$ & $0.160 *(0.0761)$ \\
\hline & Age & $0.00684(0.0115)$ & $-0.0127(0.0139)$ \\
\hline & Size of land holdings & $0.00690(0.00924)$ & $-0.00185(0.00824)$ \\
\hline & Own private tube well & $0.0325(0.176)$ & $-0.147(0.243)$ \\
\hline & Member of dominant Baradari & $0.0219(0.347)$ & $1.248 * *(0.471)$ \\
\hline & Feel accepted in community & $-0.0565(0.200)$ & $0.0167(0.283)$ \\
\hline & Trust index & $-0.0203(0.267)$ & $0.0332(0.348)$ \\
\hline \multirow[t]{2}{*}{ Group variables } & Number of castes in group & $0.0254(0.116)$ & $0.0228(0.294)$ \\
\hline & Network density of social relations & $0.0879(0.123)$ & $-0.0314(0.0683)$ \\
\hline \multirow[t]{22}{*}{ Game variables } & Round & $0.0127(0.0174)$ & $0.157^{*}(0.0663)$ \\
\hline & 1st player position & - & - \\
\hline & 2nd player position & $0.0170(0.335)$ & $-0.514(0.514)$ \\
\hline & 3rd player position & $0.259(0.355)$ & $-1.241 * *(0.430)$ \\
\hline & 4th player position & $-0.320(0.399)$ & $-1.259 \dagger(0.764)$ \\
\hline & 5th player position & $-0.0282(0.340)$ & $-3.250 * *(0.997)$ \\
\hline & Extraction $(t-1)$ & $-0.0233 * *(0.00658)$ & $0.119 * *(0.0188)$ \\
\hline & Gini-coefficient for earnings $(t-1)$ & $-1.569(0.975)$ & $-4.671(3.015)$ \\
\hline & Share in investment & - & $-13.49 * *(2.979)$ \\
\hline & $\begin{array}{l}\text { Mean extraction of all other } \\
\text { participants }(t-1)\end{array}$ & - & $-0.0915^{* *}(0.0326)$ \\
\hline & Group investment $(t-1)$ & $0.0760 * *(0.0161)$ & - \\
\hline & $\mathrm{C} \uparrow \times$ treatment phase & $-0.0565(0.334)$ & $-0.686(1.037)$ \\
\hline & $\mathrm{TA} \times$ treatment phase & $-0.0223(0.305)$ & $-0.389(0.871)$ \\
\hline & $\mathrm{P} \times$ treatment phase & $-0.211(0.435)$ & $-2.154 *(1.040)$ \\
\hline & IC $\times$ treatment phase & $-0.154(0.219)$ & $-1.250(0.901)$ \\
\hline & Received C treatment $(t-1)$ & $0.694 *(0.284)$ & $0.0171(0.616)$ \\
\hline & Received TA treatment $(t-1)$ & $-0.0290(0.373)$ & $1.066(0.789)$ \\
\hline & Received $\mathrm{P}$ treatment $(t-1)$ & $-0.112(0.375)$ & $0.475(0.634)$ \\
\hline & Initiated TA treatment $(t-1)$ & $0.406(0.312)$ & $0.786(1.096)$ \\
\hline & Initiated $\mathrm{C}$ treatment $(t-1)$ & $0.173(0.345)$ & $0.553(1.139)$ \\
\hline & Initiated $\mathrm{P}$ treatment $(t-1)$ & $-0.628(0.638)$ & $2.269 * *(0.879)$ \\
\hline & Constant & $5.308 * *(1.136)$ & $17.98 * *(1.178)$ \\
\hline \multirow[t]{5}{*}{ Random-effects parameters } & Village & $-16.55(103.3)$ & $-16.21(85.38)$ \\
\hline & Group & $-0.514 *(0.257)$ & $0.577(0.470)$ \\
\hline & Residual & $0.838 * *(0.0583)$ & $1.827 * *(0.0743)$ \\
\hline & Number of players & 160 & 160 \\
\hline & Number of observations & 2410 & 2410 \\
\hline
\end{tabular}

$\dagger P<0.1, * P<0.05, * * P<0.01$.

$\dagger$ Treatments consisted of institutions for sanctioning the water use of other participants: $\mathrm{C}=$ communication, $\mathrm{TA}=$ traditional authority, $\mathrm{P}=$ punishment, or IC = institutional choice.

participant had used the $\mathrm{C}$ treatment against his group member (s) in the last round. Similarly, Received C treatment $(t-1)$ is 1 if the participant had received the $\mathrm{C}$ treatment by one or more of his group members. In this way, we can see whether receiving or giving any particular treatment had an effect on behavior in the subsequent round.

We calculated separate models to analyze different aspect of treatments. In the first model, we only looked at the overall effect of treatments, whereas in the second model, we looked at the both the overall and the direct effect of treatments. There were no significant differences in the investment level between different treatments (Table 2). The results also confirm the notion that the position occupied by the players had a large effect on player earnings. Downstream players earned comparatively less than their upstream counterparts. One important result, which is somewhat contradictory to widespread experimental findings, is that the earnings increased over time as indicated by the relatively high positive coefficient of the variable "round number".

The introduction of institutions did not have a substantial effect on individual earnings. The only robust and significant finding is that the introduction of the $\mathrm{P}$ treatment (indicated by $\mathrm{P} \times$ treatment phase) led to a substantial decrease in player earnings. Interestingly, the direct treatment variable suggests that players in the $\mathrm{P}$ groups who initiated punishments maintained their baseline earning levels in that particular round. The sum of the coefficients for $\mathbf{P} \times$ treatment phase and Initiated $\mathrm{P}$ treatment $(t$ $-1)$ is almost zero. Introducing a punishment treatment therefore results in an environment in which using punishment results in greater earnings in the subsequent round for the player initiating the treatment, but over the course of treatment rounds, average earnings are less than baseline earnings. 
Our results further indicate that participants increased their investment if they received the $\mathrm{C}$ treatment in the previous round. To understand the distribution of resources within a group, we focused on the effect of player position on their investment and extraction decisions by comparing the investment level by treatment and player position between the baseline and treatment phases of the experiment (Fig. 8). We also calculated separate mixed-effects models for players in different positions. This allowed us to perform deeper analysis by studying the effects of treatments on each specific player position. The regression model (Appendix 4, Table A4.2) confirms the first impression of the graphical analysis; none of the sub-groups showed any significant change in the amount invested in the CPR from the baseline to the treatment phase of the experiment. We do not find any evidence for direct treatment effects on the investments of communication for any player position.

Fig. 8. Average investment depending on player position before and after the introduction of sanction treatments.

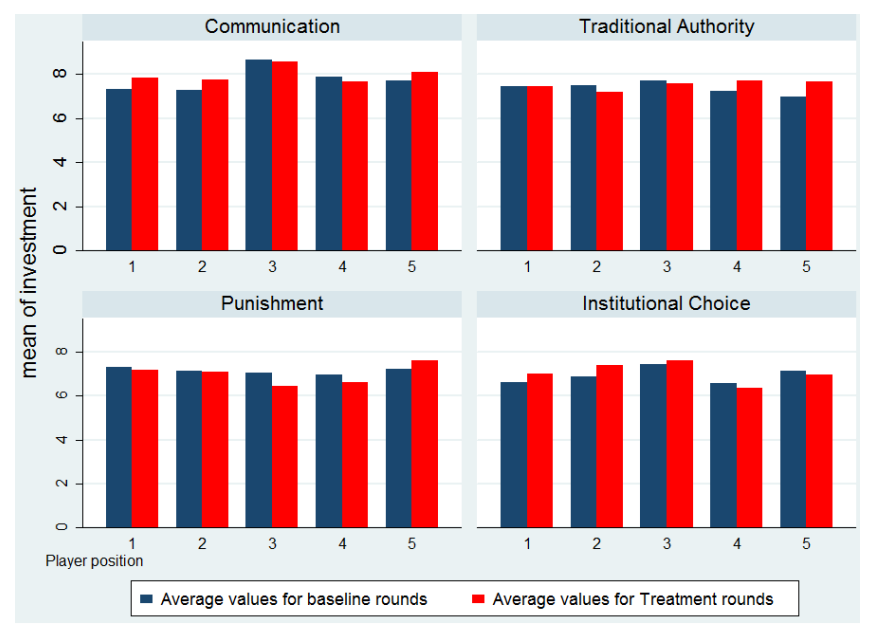

To take a closer look at the distribution of available resources and how this changes with the introduction of treatments, we compared tokens earned from extraction by player position (Fig. 9). We calculated separate mixed-effects models for players in different positions to test for the statistical significance of these developments. We included the group investment level to control for the amount of resource produced, which allowed us to look at the distributive aspect more closely (Table 3 ). The results indicate that tokens earned from extraction by tail-users increased over time. The variable "round number" is positive and statistically significant for players 3, 4, and 5 only. This suggests that groups progressively learned how to improve the share of water extracted by tail-users and distribute their resources more equitably. This is also confirmed by looking at the development of the gini-coefficient of group earnings, where there is a general decline in values (Appendix 5). For all treatments, the tokens earned from extraction by the most disadvantaged players (players 4 and 5) did not show any significant increase. In contrast, the introduction of $\mathrm{C}$ and $\mathrm{P}$ significantly decreased the extraction by head-users. Nevertheless, this did not translate into an increase in earnings for tail-users. Furthermore, we found that initiating the $\mathrm{P}$ treatment is only directly effective for head-users.

\section{Group-level analysis}

For group-level analyses, we looked at the overall welfare effects on the group level through the development of the groups' total investments and earnings (Table 4). With respect to game-level variables, we found that higher levels of inequality (in both investment and extraction) in the previous round led to significantly lower investment. The variables Gini-coeffecient investment in $t-1$ and Gini-coefficient earnings in $t-1$ were both negative in the investment models. There were similar results from individual players' investment decisions (Appendix 4, Table A.4.2), which seem to suggest that inequality in earnings is especially important for tail-users, and that greater inequality leads to decreased investment by them. This indicates the importance of equitable distribution of resources within the group and is in line with the mutual vulnerability cooperation framework. In this regard, our results are broadly consistent with previous studies, especially that of Janssen et al. (2012), which looked at the issue of inequality and CPR provision in more detail.

Fig. 9. Average earnings depending on player position for different sanction treatments.

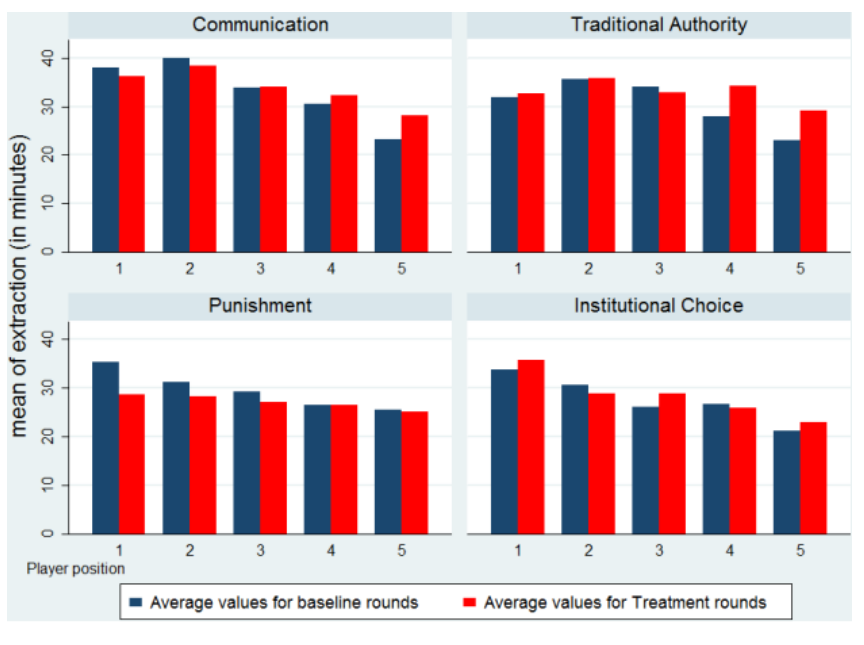

The models also confirm that groups were able to increase the tokens earned over experimental rounds (Table 4). This resulted from increased extraction by tail-users, which led to more efficient distribution of resources (Table 3). This is also indicated by the decrease in gini-coefficients over time (Appendix 5).

The model explaining group earnings also indicates that the only significant effect of institutions on group earnings occurs for $\mathrm{P}$ groups. Group welfare decreased substantially when participants were given the opportunity to punish other players in their group. As discussed earlier, the introduction of $\mathrm{P}$ effectively reduced resource extraction by head-users (Table 3 ). Nevertheless, this did not result in an increase in earnings for tail-users. We observed a decrease in earning inequality for $\mathrm{P}$ groups, but this was accompanied by a decrease in group welfare. This is surprising because a redistribution of resources from head- to tail-users should have increased the marginal utility per unit extracted. The explanation for this anomaly, at least for the $\mathbf{P}$ groups, lies in the amount of water wasted by the groups. The introduction of $\mathrm{P}$ caused a four-fold increase in the amount of water not used by the groups (Appendix 6). 
Table 3. Mixed-effects regression results explaining the total tokens earned from water extraction depending on player position. Numbers are coefficients, with robust standard errors in parentheses.

\begin{tabular}{|c|c|c|c|c|c|c|}
\hline Variable level & Variable & Player 1 & Player 2 & Player 3 & Player 4 & Player 5 \\
\hline \multirow[t]{13}{*}{ Individual level } & Education level & $\begin{array}{l}-0.155 \\
(0.227)\end{array}$ & $\begin{array}{c}0.224 \\
(0.308)\end{array}$ & $\begin{array}{c}-0.0545 \\
(0.210)\end{array}$ & $\begin{array}{l}0.621^{* *} \\
(0.172)\end{array}$ & $\begin{array}{l}0.00741 \\
(0.308)\end{array}$ \\
\hline & \multirow[t]{2}{*}{ Age } & -0.0470 & 0.0173 & $-0.0458^{*}$ & $0.0577^{* *}$ & -0.00381 \\
\hline & & $(0.0315)$ & $(0.0378)$ & $(0.0231)$ & $(0.0182)$ & $(0.0291)$ \\
\hline & \multirow[t]{2}{*}{ Size of land holdings } & $0.0836^{*}$ & -0.0602 & 0.0197 & 0.0129 & 0.0431 \\
\hline & & $(0.0409)$ & $(0.0402)$ & $(0.0408)$ & $(0.0148)$ & $(0.0269)$ \\
\hline & \multirow[t]{2}{*}{ Own private tube well } & -0.236 & 0.0804 & -0.539 & 0.235 & -0.222 \\
\hline & & $(0.574)$ & $(0.383)$ & $(0.381)$ & $(0.466)$ & $(0.549)$ \\
\hline & Member of dominant & 1.507 & $4.062 * *$ & -0.400 & 0.319 & $2.579 * *$ \\
\hline & Baradari & $(1.141)$ & $(1.120)$ & (1.186) & $(0.549)$ & $(0.658)$ \\
\hline & Feel accepted in & 0.651 & 0.0567 & -0.550 & -0.275 & -0.547 \\
\hline & community & $(0.479)$ & $(0.937)$ & $(0.568)$ & $(0.295)$ & $(0.415)$ \\
\hline & Trust index & $1.503 * *$ & -0.303 & -0.293 & $-0.962 * *$ & $1.755 \dagger$ \\
\hline & & $(0.496)$ & $(0.780)$ & $(0.540)$ & $(0.343)$ & $(0.912)$ \\
\hline \multirow[t]{4}{*}{ Group variables } & \multirow{2}{*}{$\begin{array}{l}\text { Number of castes in } \\
\text { group }\end{array}$} & -0.380 & -0.0349 & $-0.562 \dagger$ & $0.444 \dagger$ & 0.0230 \\
\hline & & $(0.512)$ & $(0.490)$ & $(0.323)$ & $(0.258)$ & $(0.529)$ \\
\hline & \multirow{2}{*}{$\begin{array}{l}\text { Network density of } \\
\text { social relations }\end{array}$} & -0.0123 & -0.453 & $-0.917 * *$ & 0.176 & -0.166 \\
\hline & & $(0.247)$ & $(0.587)$ & $(0.206)$ & $(0.525)$ & $(0.389)$ \\
\hline \multirow[t]{20}{*}{ Game variables } & \multirow[t]{2}{*}{ Group investment } & $0.551 * *$ & $0.574 * *$ & $0.737 * *$ & $0.803^{* *}$ & $0.706^{* *}$ \\
\hline & & $(0.0851)$ & $(0.0546)$ & $(0.0397)$ & $(0.0338)$ & $(0.0408)$ \\
\hline & \multirow[t]{2}{*}{ Round number } & 0.131 & -0.0311 & $0.224 *$ & $0.166 \dagger$ & $0.152 * *$ \\
\hline & & $(0.0911)$ & $(0.0678)$ & $(0.0936)$ & $(0.0887)$ & $(0.0577)$ \\
\hline & \multirow{2}{*}{$\begin{array}{l}\text { Gini-coefficient for } \\
\text { earnings }(t-1)\end{array}$} & -1.997 & -3.520 & $3.659^{*}$ & $4.579^{*}$ & -1.642 \\
\hline & & $(2.980)$ & $(4.461)$ & $(2.029)$ & $(2.170)$ & $(2.359)$ \\
\hline & \multirow{4}{*}{$\begin{array}{l}\text { Mean extraction of all } \\
\text { other participants }(t-1) \\
\text { Extraction }(t-1)\end{array}$} & $-0.0747^{*}$ & 0.00903 & -0.0966 & -0.0476 & -0.0496 \\
\hline & & $(0.0311)$ & $(0.0441)$ & $(0.0611)$ & $(0.0301)$ & $(0.0477)$ \\
\hline & & $0.0529 *$ & -0.0343 & $0.0751^{*}$ & 0.0305 & $0.0613 \dagger$ \\
\hline & & $(0.0214)$ & $(0.0504)$ & $(0.0377)$ & $(0.0255)$ & $(0.0338)$ \\
\hline & \multirow[t]{2}{*}{$\mathrm{C} \dagger \times$ treatment phase } & $-1.494^{*}$ & 0.248 & $-1.946^{* *}$ & -0.567 & -0.477 \\
\hline & & $(0.583)$ & $(1.032)$ & $(0.753)$ & (1.493) & (1.464) \\
\hline & \multirow[t]{2}{*}{$\mathrm{TA} \times$ treatment phase } & -1.456 & -0.228 & -1.135 & $1.657 \dagger$ & 0.959 \\
\hline & & $(1.191)$ & $(0.954)$ & (1.197) & $(0.969)$ & $(1.271)$ \\
\hline & \multirow[t]{2}{*}{$\mathrm{P} \times$ treatment phase } & $-3.709^{*}$ & -0.582 & -1.763 & -0.266 & 0.851 \\
\hline & & $(1.677)$ & $(0.863)$ & $(1.331)$ & $(0.889)$ & $(1.445)$ \\
\hline & \multirow[t]{2}{*}{ IC $\times$ treatment phase } & -0.263 & -0.993 & -0.726 & -1.255 & -1.181 \\
\hline & & $(0.805)$ & $(1.038)$ & $(0.724)$ & $(1.035)$ & $(1.200)$ \\
\hline & \multirow[t]{2}{*}{ Constant } & $-7.063^{* *}$ & $-7.677 \dagger$ & $-8.730^{*}$ & $-22.23 * *$ & $-20.66^{* *}$ \\
\hline & & $(2.677)$ & $(4.403)$ & $(3.623)$ & $(2.708)$ & $(2.904)$ \\
\hline \multirow{8}{*}{$\begin{array}{l}\text { Random-effects } \\
\text { parameters }\end{array}$} & \multirow[t]{2}{*}{ Village } & 0.0270 & $0.659^{*}$ & 0.369 & -1.332 & 0.297 \\
\hline & & $(0.371)$ & $(0.283)$ & $(0.375)$ & $(6.445)$ & $(0.269)$ \\
\hline & \multirow[t]{2}{*}{ Group } & -0.156 & $0.666^{* *}$ & -16.17 & 0.0271 & -0.554 \\
\hline & & $(0.596)$ & $(0.245)$ & $(70.03)$ & $(0.588)$ & $(0.810)$ \\
\hline & \multirow[t]{2}{*}{ Residual } & $1.643 * *$ & $1.489 * *$ & $1.575^{* *}$ & $1.539 * *$ & $1.631 * *$ \\
\hline & & $(0.0978)$ & $(0.0946)$ & $(0.0807)$ & $(0.0438)$ & $(0.0487)$ \\
\hline & Number of players & 32 & 32 & 32 & 32 & 32 \\
\hline & Total $N$ & 482 & 482 & 482 & 482 & 482 \\
\hline
\end{tabular}

$\dagger P<0.1, * P<0.05, * * P<0.01$.

$\dagger$ Treatments consisted of institutions for sanctioning the water use of other participants: $\mathrm{C}=$ communication, $\mathrm{TA}=$ traditional authority, $\mathrm{P}=$ punishment, or IC = institutional choice.

Four of eight groups under the $\mathrm{P}$ treatment experienced wasting of water in the treatment phase. In contrast, only one group with the $\mathrm{C}$ and IC treatments each and two groups with the TA treatment did not fully use the available water. In addition, groups that used the P treatment more frequently were the ones with the highest amounts of water wasted. Three of the four $\mathrm{P}$ groups that did not fully use the available water ranked in the top three in terms of the number of players who were targeted by the $\mathrm{P}$ treatment during the treatment phase. Interestingly, in IC groups where the $P$ treatment was used quite often, we did not see any effect on the wastage of resources. This may be because in IC groups, $\mathrm{P}$ was often accompanied by the use of TA and $\mathrm{C}$.

\section{DISCUSSION}

\section{Group investment}

Similar to most public good and CPR experiments, participants in our experiments both invested and earned amounts greater than the levels predicted by the Nash equilibrium, but below the social optimum (Ledyard 1994, Zelmer 2003, Chaudhuri 2011). Even without communication or institutional incentives options, 
Table 4. Mixed-effects regression results explaining the total tokens invested and earned by groups. Numbers are coefficients, with robust standard errors in parentheses.

\begin{tabular}{|c|c|c|c|}
\hline Variable level & Variable & $\begin{array}{l}\text { Group investment } \\
\text { (rounds 2-18) }\end{array}$ & $\begin{array}{l}\text { Group earnings } \\
\text { (rounds 2-18) }\end{array}$ \\
\hline \multirow[t]{5}{*}{ Individual level } & Variation in age & $-0.458(0.371)$ & $-0.265(0.398)$ \\
\hline & Variation in size of land holding & $-0.165(0.311)$ & $-0.195(0.318)$ \\
\hline & Variation in education level & $-1.276(3.716)$ & $-1.278(4.045)$ \\
\hline & Number of castes in group & $-0.865(3.093)$ & $-0.409(2.616)$ \\
\hline & Network density of social relations & $3.086(8.918)$ & $2.021(8.670)$ \\
\hline \multirow[t]{4}{*}{ Village level } & Number of households & $-0.0028(0.0034)$ & $-0.003(0.012)$ \\
\hline & Head-user or tail-user & $0.394(0.719)$ & $0.436(1.986)$ \\
\hline & Distance to market & $0.152 *(0.0629)$ & $-0.108(0.232)$ \\
\hline & Frequency of water disputes & $-0.00150(0.293)$ & $0.935(1.634)$ \\
\hline \multirow[t]{10}{*}{ Game level } & Round & $0.816^{*}(0.369)$ & $0.634 * *(0.160)$ \\
\hline & $\begin{array}{l}\text { Gini-coefficient for investment }(t- \\
\text { 1) }\end{array}$ & $-20.83 *(9.810)$ & $6.530(11.44)$ \\
\hline & Gini-coefficient for earnings $(t-1)$ & $-17.25(21.03)$ & $3.424 *(0.179)$ \\
\hline & Group investment & - & $0.885(4.076)$ \\
\hline & $\begin{array}{l}\text { Gini-coefficient for extraction }(t- \\
\text { 1) }\end{array}$ & - & \\
\hline & $\mathrm{C} \dagger \times$ treatment phase & $0.0754(1.796)$ & $-2.251(5.322)$ \\
\hline & $\mathrm{TA} \times$ treatment phase & $-0.0712(1.594)$ & $-1.244(4.167)$ \\
\hline & $\mathrm{P} \times$ treatment phase & $-1.447(2.299)$ & $-9.033+(5.466)$ \\
\hline & $\mathrm{IC} \times$ treatment phase & $-1.049(1.349)$ & $-5.456(4.526)$ \\
\hline & Constant & $35.40 * *(4.242)$ & $84.38 * *(12.18)$ \\
\hline \multirow[t]{5}{*}{ Random effects parameters } & Village & $-15.98(66.2)$ & $-15.50(228.1)$ \\
\hline & Group & $0.960 *(0.378)$ & $2.073(3.449)$ \\
\hline & Residual & $1.826 * *(0.0548)$ & $2.479 * *(0.0297)$ \\
\hline & Number of groups & 32 & 32 \\
\hline & Number of observations & 482 & 482 \\
\hline
\end{tabular}

$\dagger P<0.1, * P<0.05, * * P<0.01$.

$\dagger$ Treatments consisted of institutions for sanctioning the water use of other participants: $\mathrm{C}=$ communication, $\mathrm{TA}=$ traditional authority, $\mathrm{P}=$ punishment, or IC = institutional choice.

the average group investment was $98 \%$ of the social optimal investment benchmark. Average group earnings during the baseline rounds were $74 \%$ of the social optimum.

The overall level of investment in our experiment is partially comparable to that of Janssen et al. (2011b) who found that average investment levels are very high for irrigation games. Other studies using a similar experimental design, however, found much lower investment levels (Cardenas et al. 2010, Janssen et al. 2012, Otto and Wechsung 2014). Furthermore, head-users in Janssen et al. $(2011 b)$ invested at much higher levels than tail-users. This is in contrast to our results, where the player position did not affect investments.

In many public good experiments, participants managed to exhibit similar levels of contributions in one-shot games or in the starting round of repeated games (Ledyard 1994). Nevertheless, one of the most consistent findings in experimental literature is that in the absence of the ability to communicate or sanction, the level of investment falls to only $30-40 \%$ of players' endowment (Ostrom et al. 1992, Ledyard 1994, Fehr and Gächter 2000, Balliet 2010). Chaudhuri (2011) list different factors that have been put forward to explain this decline such as confusion or decision errors (Andreoni 1995, Palfrey and Prisbrey 1997, Anderson and Putterman 2006) and a combination of learning to play the dominant strategy and strategic play by self- interested players (Andreoni 1988, Andreoni and Croson 2008). In contrast to these studies, participants in our experiment maintained a very high level of investment throughout the experiment rounds and exhibited increasingly cooperative behavior over the rounds.

Our observed high level of investment and increasingly cooperative behavior were likely a result of the availability of social information on individual extraction levels. One of our motivations to adapt the design of Janssen et al. (2011b) was to increase the external validity. There is a low degree of privacy in the researched communities. According to Carpenter and Seki (2011) and Henrich et al. (2010), participant behavior in experimental settings is based on their real-life experiences. Most of the participants in our experiments deal with each other on almost a daily basis, and they can easily observe each others' actions. Furthermore, provision of labor and resources for the management of irrigation infrastructure is a typical challenge for them. It is likely that the studied community has developed strong norms based on interactions over a long period of time, which help them to overcome these social dilemmas. Our players might have used this contextual information during the experiment.

Revealing the individual extraction levels of all group members at the end of each round is a critical departure from Janssen et al. 's (2011b) design. Our design does not allow us to make clear statements about the effect of anticipated approval or disapproval on the players' decisions. Nevertheless, it is likely that this adaptation is responsible for a large share of the high levels of 
efficiency encountered in our game, which do not match the data reported from other field experiments using this game (see Janssen et al. 2012).

The fact that our players improve their individual and group earnings over the game rounds can potentially be explained by the establishment of a social norm supported by the social information. These norms could drive the groups increasingly closer to the social optimum. As expected, the gini-coefficient of extractions became lower over the rounds, which indicates that the group's individuals learned to adjust their extractions to each other (Appendix 5). This increase in social efficiency over the rounds is in contradiction to Croson and Shang's (2008) findings. If the downward effect was stronger than the upward one, extraction levels should have been increasing, leading to worse social outcomes.

Individual-level investments and earnings: distributional aspects With respect to distributional aspects, players in advantageous positions with preferential access to the CPR had significantly higher earnings as a result of higher levels of appropriation. This is consistent with findings of other studies on asymmetric access (Budescu et al. 1997, Cardenas et al. 2008, Janssen et al. 2011b). It could be expected that the individuals who lose out punish the winners by withdrawing their contributions. However, this is not the case; rather, we found a learning effect whereby groups are able to increase their tail-users' earnings over time, which results in more efficient use of resources and increased group earnings. Also, unlike Janssen et al. (2011b) and other studies, the average earnings for even the most disadvantaged players were greater than the level predicted by Nash equilibrium analysis. This suggests that even the most disadvantaged users have some incentive to maintain their investments for the provision of CPR.

Ostrom and Gardner (1993) suggest that in stable groups, headusers are expected to invest significantly more than their tail-end counterparts. In contrast to this theoretical prediction, Punjabi farmers invested on average similar amounts regardless of their position in the irrigation system. They seemed to exhibit more tolerance toward inequalities in earnings. One potential explanation, unrelated specifically to irrigation, could be that Pakistan is considered a hierarchical society (Hofstede 2001), which means that people accept a hierarchical order in which everyone has a place without any need for further justification. An alternative explanation could be that local farmers' norms regulating extraction decisions are weaker compared to norms guiding their decisions on the provision of public or common goods. During discussions after the experiment, we found that different participants had different views of what constitutes a "fair share". This situation could be related to contradictory incentives introduced by various governance interventions in the history of the Punjab irrigation management.

We found strong evidence in support of Singleton and Taylor's (1992) concept of cooperation based on mutual vulnerabilities. First, we observed that many tail-users encouraged others to invest in the irrigation infrastructure because they most strongly rely on well-maintained and extensive irrigation systems. One real-life explanation for tail-users' strong motivation to keep the infrastructure in good condition is that water allocation is calculated on a constant amount per area basis, regardless of the location along the canal. Because transmission losses along the canal are not considered, greater transmission losses effectively mean less water for tail-users (Latif and Sarwar 1994). Also, in our experiments, tail-users earned on average more than they would in a fully noncooperative setting, as predicted by the Nash equilibrium. Furthermore, tail-users' share of extraction increased with the amount of CPR produced (Appendix 3, Fig. A3.1). Therefore, tail-users had the incentive to maintain their investment for the provision of CPR, even if their earnings were lower than those of head-users. However, at the same time, we found that greater inequality in both investments and earnings in the previous round had a negative effect on group investments (Table 3).

Second, only in very few cases were head-users seen to be freeriding or maximizing their gains. In most cases, they showed some restraint in their extraction decisions and did not extract the maximum possible water quantity. Head-users seemed to be taking the needs of the later users into account. They understood the importance of sharing the CPR with tail-users. The implicit threat of withdrawing or reducing cooperation might play some role in restraining head-users' extraction. Alternatively, headusers' consideration could also be interpreted as a sign of social norms coming into play. Taking these two results together, it could be argued that the mutual dependence of different players on each other is a strong motivation for maintaining cooperative behavior.

\section{Role of institutions}

Introducing institutional interventions had no significant effect on the overall level of investment and hardly any effect on earnings. In particular, there was no significant effect of the TA and IC treatments. Nevertheless, we think it is important to study both of these institutional arrangements in CPR field experiment settings. Our treatment design may inspire such future studies.

It could be argued that the treatments actually affected the investment behavior by avoiding a decline in contributions, as observed in many other experimental studies. Unfortunately, we did not let a fifth group play the treatment round without any treatment. We are therefore unable to analyze this possible effect.

Both the $\mathrm{C}$ and TA treatments can affect the incentive structure of the game by focusing on the other-regarding preferences of the participants. These treatments allowed expression of approval or disapproval. Nevertheless, the anticipated approval or disapproval experienced through the knowledge that all other group members learn about each others' extractions might have been a strong enough incentive that could not be increased by actual expressed (dis-)approval. In addition, the communication in both treatments could theoretically signal willingness to cooperate, create group identity, and help develop shared norms (Balliet 2010). The very high provision level during the baseline rounds, however, indicated that the groups were willing to cooperate even before communicating. It is difficult to improve upon this outcome. The experiment simulates a situation that is very similar to the participants' real-life experiences, and it is likely that participants have a well-established group identity. If that is this case, why did they use the treatments at all? It is possible that they believed they could still improve their outcomes, although this did not occur.

The $\mathrm{P}$ treatment more directly changed the incentive structure of the game and in fact showed one of the predicted effects. The 
treatments were mostly used to address the appropriation aspects of the irrigation dilemma. This is not surprising because only the individual appropriation decisions were revealed after every round. Theoretically, a rational player would expect to be punished with a low probability only. Nevertheless, the costs of withdrawing cooperation as an alternative sanction are perceived to be higher than the transaction costs associated with punishments. Therefore, we suspect that strongly motivated participants used the $\mathrm{P}$ treatment as a low-cost retaliatory option instead of withdrawing from the game. Our results show that the external punishment mechanism is effective in reducing extraction levels of head-users. Nevertheless, this does not translate into a beneficial effect for tail-user earnings or overall group welfare.

The fact that the $\mathrm{P}$ treatment reduces group welfare suggests the possibility of crowding out, which is often observed in $\mathrm{P}$ treatments in public goods and CPR games (Cardenas et al. 2000, Vollan 2008). Nevertheless, in our case, punishment did not erode the strong intrinsic norms of public good provision or the restraint from maximum resource extraction. On the contrary, head-users reduced their resource extraction. Nevertheless, they left more water to the tail-users than would be productive, taking into account the decreasing marginal productivity of very high water extractions. Repeatedly, more water than the maximum extractable amount (50 units) was left for the tail-users. In addition, the tail-users did not increase their resource extraction. It is interesting to note that tail-users were more likely to be targeted by treatments if they extracted below the group average. The net effect was an increase in the amount of resource wasted, resulting in sub-optimal resource use and a decrease in overall group welfare.

Compared to the other treatments, $\mathrm{P}$ offered the least opportunity to convey concerns accurately and directly among players. Rather, the indirect signaling in the form of fines possibly resulted in even greater difficulty in coordinating actions. Signaling norms likely could be achieved sufficiently by the social information regarding players' water extraction levels. We observed a weak pattern that suggested that a higher frequency of using the $\mathrm{P}$ treatment increased the struggle to coordinate. Interestingly, there was no such increased inefficiency in the IC groups, which could use communication in addition to punishment. An alternative or additional explanation could be that the $\mathrm{P}$ treatment induced an internalized norm to the players that higher scale externalities should be taken into account, thereby changing their strategy from maximizing group welfare to simply trying to save water. Further research is needed to interpret our results reliably.

\section{CONCLUSION}

We studied a community for which the irrigation system has unique historical and material value. The very existence and sustainability of extensive agriculture was and is dependent on this irrigation system. We found that the participants in our experiment were able to provide the $\mathrm{CPR}$ at a reasonable and stable level, even in the presence of the asymmetric access challenge. We found evidence in favor of the proposition that mutual dependence on each other helped maintain a symbiotic relationship among participants. The distribution of resources proved to be a bigger challenge than resource provision for participants. Nevertheless, with regard to both challenges, the participants showed positive learning effects by decreasing inequality in the distribution of resources and increasing group welfare over time.

Our results are applicable mostly for tertiary-level management, where communities have regular interactions that allow social norms to develop. Furthermore, free-and-easy access to information about various aspects of the irrigation system allowed users to observe the effects of their and other users' actions. However, in large irrigation systems such as the Indus basin irrigation system in Pakistan, tertiary-level management is only one of the challenges. Secondary- and primary-level irrigation management involves different communities who may not have the required social capital. Similarly, the availability and reliability of information is also a problem at these levels. Further research should examine the coordination and cooperation among stakeholders involved in secondary- and primary-level management and whether they differ substantially from local communities managing tertiary-level infrastructure.

One implication of Singleton and Taylor's (1992) concept of cooperation based on mutual vulnerabilities is that policy makers have to be especially mindful of technological and social interventions that decrease this mutual interdependence. This interdependence can potentially be reduced by the widespread development of public as well as private tube wells, which decreases the dependence on canal irrigation, although at a higher cost than canal water. Kajisa et al. (2007) report, for instance, that the drilling of private wells reduced collective action in Indian farmer communities and lead to higher inequality. Although our study did not show less cooperative behavior among players who had access to private tube wells, the question as to whether or not development of wells can lead to collective action failure remains a salient research question that should be considered in future. The fact that institutional interventions had no significant effect on group cooperation raises the question whether any institutional change can improve social outcomes. Given this result, how can we explain actual institutional change? Is there a risk that resources invested in more participatory water management are wasted? Even though we tried to mimic historical and present institutions, the experiment obviously does not fully reflect reality. Reports of the Irrigation Department and Government of Punjab indicate that the large-scale top-down water provision scheme is facing serious challenges. Our experiments with small water user groups in Punjab indicate that social information in terms of transparency of individual water extraction levels in combination with social norms is sufficient to maintain reasonably high cooperation.

It should be highlighted that revealing the extraction levels of all players may have substantially changed the structure of the game. Anticipated benefits of pride or costs of shame may result in a more cooperative dominant strategy. If this is the case, additional institutional incentives are unlikely to affect behavior. In planning our study, we underestimated the effect of social information. In future research, we recommend introducing social information as a treatment to differentiate the effects of social information and institutional treatments.

Our main argument for revealing the extraction behavior throughout the game was the fact that farmers in real life can indeed observe others' water extractions. This leads to important policy implications. If availability of social information in these 
communities creates such strong incentives to cooperate that external institutional incentives are ineffective, then external institutional interventions should only be applied with great care. Taking into account that major historical and current institutional changes have been initiated externally, policy makers should always critically question whether the intended interventions would really lead to the desired results. Special caution is required with regard to the application of external sanctions; they bear not only the widely reported risk of crowding out, but they also potentially create additional coordination problems. Our results suggest that external sanctions may not be the most effective solution to social dilemmas in close-knit communities. This does not mean that external sanctions may not be an appropriate instrument in specific social-ecological systems. Following Ostrom's (2007) line of thinking, we acknowledge that the complex interplay of social and ecological features of a system determine which set of governance instruments has the comparative advantage. In the particular setting we studied, external sanctions led to social losses due to inefficient use of resources.

The study of interactions between formal and informal institutions while taking into account the historical background of the communities requires further attention. We add to this discussion by incorporating a unique, local institution (panchayat), and comparing and contrasting its performance with two of the most widely studied institutions (communication and external sanctions). Hopefully, our experiments will inspire researchers to incorporate alternative local institutions in the design of future experimental studies.

Responses to this article can be read online at: http://www.ecologyandsociety.org/issues/responses. $\mathrm{php} / 7532$

\begin{abstract}
Acknowledgments:
We greatly appreciate the support provided by Dr. Basharat and Mr. Khalid. Their support was very critical for the organization of our successful field work. We are also grateful to the team of students, in particular, Muhammad Asim, Amin-ul-haq, Nazar Abbas, Muhammad Iftikhar, Muhammad Essa, Muhammad Saqib, and Muhammad Bilal, for their excellent assistance in conducting the experiments. Most importantly, we thank all the people who enthusiastically and patiently participated in the experiments.
\end{abstract}

\section{LITERATURE CITED}

Agnihotri, I. 1996. Ecology, land use and colonisation: the canal colonies of Punjab. Indian Economic and Social History Review 33(1):37-58. http://dx.doi.org/10.1177/001946469603300102

Ali, I. 1987. Malign growth? Agricultural colonization and the roots of backwardness in the Punjab. Past and Present 114 (1):110-132. http://dx.doi.org/10.1093/past/114.1.110

Ali, I. 1988. The Punjab under Imperialism, 1885-1947. Princeton University Press, Princeton, New Jersey, USA.

Anderson, C. M., and L. Putterman. 2006. Do non-strategic sanctions obey the law of demand? The demand for punishment in the voluntary contribution mechanism. Games and Economic Behavior 54(1):1-24. http://dx.doi.org/10.1016/j.geb.2004.08.007

Andreoni, J. 1988. Why free ride?: Strategies and learning in public-goods experiments. Journal of Public Economics 37 (3):291-304. http://dx.doi.org/10.1016/0047-2727(88)90043-6

Andreoni, J. 1995. Cooperation in public-goods experiments: kindness or confusion? American Economic Review 85 (4):891-904.

Andreoni, J., and R. Croson. 2008. Partners versus strangers: random rematching in public goods experiments. Pages 776-783 in Handbook of Experimental Economics Results. Volume 1. Elsevier, Amsterdam, The Netherlands. http://dx.doi.org/10.1016/ $\underline{\text { S1574-0722(07)00082-0 }}$

Badruddin, M. 1993. An overview of irrigation in Pakistan. International Irrigation Management Institute, Lahore, Pakistan.

Balliet, D. 2010. Communication and cooperation in social dilemmas: a meta-analytic review. Journal of Conflict Resolution 54(1):39-57. http://dx.doi.org/10.1177/0022002709352443

Bandaragoda, D. J., and S. ur Rehman. 1995. Warabandi in Pakistan's canal irrigation systems: widening gap between theory and practice. International Irrigation Management Institute, Colombo, Sri Lanka. [online] URL: http://publications.iwmi.org/ pdf/H 17571i.pdf.

Bardhan, P. 2000. Irrigation and cooperation: an empirical analysis of 48 irrigation communities in South India. Economic Development and Cultural Change 48(4):847-865. http://dx.doi. org/10.1086/452480

Bicchieri, C. 2002. Covenants without swords: group identity, norms, and communication in social dilemmas. Rationality and Society 14(2):192-228. http://dx.doi.org/10.1177/1043463102014002003

Budescu, D. V., W. T. Au, and X.-P. Chen. 1997. Effects of protocol of play and social orientation on behavior in sequential resource dilemmas. Organizational Behavior and Human Decision Processes 69(3):179-193. http://dx.doi.org/10.1006/obhd.1997.2684

Cardenas, J.-C., M. Janssen, and F. Bousquet. 2008. Dynamics of rules and resources: three new field experiments on water, forests and fisheries. Pages 319-345 in J. A. List and M. K. Price, editors. Handbook on experimental economics and the environment. Edward Elgar, Cheltenham, UK. http://dx.doi.org/10.4337/9781781009079.00020

Cardenas, J. C., J. Stranlund, and C. Willis. 2000. Local environmental control and institutional crowding-out. World Development 28(10):1719-1733. http://dx.doi.org/10.1016/S0305-750X (00)00055-3

Carpenter, J., and E. Seki. 2011. Do social preferences increase productivity? Field experimental evidence from fishermen in Toyama Bay. Economic Inquiry 49(2):612-630. http://dx.doi. org/10.1111/j.1465-7295.2009.00268.x

Chaudhuri, A. 2011. Sustaining cooperation in laboratory public goods experiments: a selective survey of the literature. Experimental Economics 14(1):47-83. http://dx.doi.org/10.1007/ $\underline{\text { s10683-010-9257-1 }}$ 
Cheema, A., S. K. Mohmand, and M. Patnam. 2009. Colonial proprietary elites and institutions: the persistence of de facto political dominance. Institute of Development Studies, University of Sussex, Brighton, UK. http://dx.doi.org/10.2139/ssrn.1473910

Coleman, J. S. 1987. Norms as social capital. Pages 133-155 in G. Radnitzky and P. Bernholz, editors. Economic imperialism: the economic approach applied outside the field of economics. Paragon House Publishers, New York, New York, USA.

Coward, E. W. Jr., and G. Levine. 1987. Studies of farmermanaged irrigation systems: ten years of cumulative knowledge and changing research priorities. Pages 1-31 in International Irrigation Management Institute and Government of Nepal, editors. Public intervention in farmer-managed irrigation systems. International Irrigation Management Institute, Digana Village via Kandy, Sri Lanka. [online] URL: http://pdf.usaid.gov/ pdf docs/PNABD792.pdf.

Croson, R., and J. Shang. 2008. The impact of downward social information on contribution decisions. Experimental Economics 11(3):221-233. http://dx.doi.org/10.1007/s10683-007-9191-z

de Klein, C. H. and R. Wahaj. 1998. Institutional and physical determinants of water management performance at the tertiary level: the dynamics of watercourse maintenance in the Pakistan Punjab. International Irrigation Management Institute, Colombo, Sri Lanka. [online] URL: http://publications.iwmi.org/ pdf/H 22927i.pdf.

Deininger, K., and G. Feder. 2009. Land registration, governance, and development: evidence and implications for policy. World Bank Research Observer 24(2):233-266. http://dx.doi.org/10.1093/ wbro/lkp007

Falk, A., E. Fehr, and U. Fischbacher. 2005. Driving forces behind informal sanctions. Econometrica 73(6):2017-2030. http://dx.doi. org/10.1111/j.1468-0262.2005.00644.X

Falk, T., B. Vollan, and M. Kirk. 2012. Analysis of material, social, and moral governance in natural resource management in southern Namibia. International Journal of the Commons 6 (2):271-301. [online] URL: http://www.thecommonsjournal.org/ index.php/ijc/article/download/307/293.

Fehr, E., and S. Gächter. 2000. Cooperation and punishment in public goods experiments. American Economic Review 90 (4):980-994. http://dx.doi.org/10.1257/aer.90.4.980

Fleuret, P. 1985. The social organization of water control in the Taita Hills, Kenya. American Ethnologist 12(1):103-118. http:// dx.doi.org/10.1525/ae.1985.12.1.02a00060

Gilmartin, D. 1994. Scientific empire and Imperial science: colonialism and irrigation technology in the Indus basin. Journal of Asian Studies 53(4):1127-1149. http://dx.doi.org/10.2307/2059236

Gordon, H. S. 1954. The economic theory of a common-property resource: the fishery. Journal of Political Economy 62(2):124-142. http://dx.doi.org/10.1086/257497

Gürerk, Ö., B. Irlenbusch, and B. Rockenbach. 2006. The competitive advantage of sanctioning institutions. Science 312:108-111. http://dx.doi.org/10.1126/science.1123633

Hardin, G. 1968. The tragedy of the commons. Science 162 (3859):1243-1248. http://dx.doi.org/10.1126/science.162.3859.1243
Harrison, G. W., and J. A. List. 2004. Field experiments. Journal of Economic Literature 42(4):1009-1055. http://dx.doi. org/10.1257/0022051043004577

Henrich, J., S. J. Heine, and A. Norenzayan. 2010. The weirdest people in the world? Behavioral and Brain Sciences 33(2-3):61-83. http://dx.doi.org/10.1017/S0140525X0999152X

Hofstede, G. 2001. Culture's consequences: comparing values, behaviors, institutions, and organizations across nations. Sage, Thousand Oaks, California, USA.

Hunt, R. C. 1988. Size and the structure of authority in canal irrigation systems. Journal of Anthropological Research 44:335-355.

Janssen, M. A., J. M. Anderies, and J.-C. Cardenas. 2011a. Headenders as stationary bandits in asymmetric commons: comparing irrigation experiments in the laboratory and the field. Ecological Economics 70(9):1590-1598. http://dx.doi.org/10.1016/j. ecolecon.2011.01.006

Janssen, M. A., J. M. Anderies, and S. R. Joshi. $2011 b$. Coordination and cooperation in asymmetric commons dilemmas. Experimental Economics 14(4):547-566. http://dx.doi. org/10.1007/s10683-011-9281-9

Janssen, M. A., F. Bousquet, J.-C. Cardenas, D. Castillo, and K. Worrapimphong. 2012. Field experiments on irrigation dilemmas. Agricultural Systems 109:65-75. http://dx.doi.org/10.1016/j. agsy.2012.03.004

Javid, H. 2012. Class, power, and patronage: the landed elite and politics in Pakistani Punjab. Dissertation. London School of Economics and Political Science, University of London, London, UK.

Kajisa, K., K. Palanisami, and T. Sakurai. 2007. Effects on poverty and equity of the decline in collective tank irrigation management in Tamil Nadu, India. Agricultural Economics 36 (3):347-362. http://dx.doi.org/10.1111/j.1574-0862.2007.00212.x

Latif, M., and S. Sarwar. 1994. Proposal for equitable water allocation for rotational irrigation in Pakistan. Irrigation and Drainage Systems 8(1):35-48. http://dx.doi.org/10.1007/BF00880797

Ledyard, J. O. 1994. Public goods: a survey of experimental research. In J. H. Kagel and A. E. Roth, editors. The handbook of experimental economics. Princeton University Press, Princeton, New Jersey, USA.

Mamdani, M. 1996. Citizen and subject: contemporary Africa and the legacy of late colonialism. Princeton University Press, Princeton, New Jersey, USA.

Merrey, D. J. 1986a. The local impact of centralized irrigation control in Pakistan: a sociocentric perspective. Pages 12-25 in D. J. Merrey and J. M. Wolf, editors. Irrigation management in Pakistan: four papers. International Irrigation Management Institute, Digana Village, Sri Lanka. [online] URL: http:// publications.iwmi.org/pdf/H043839.pdf.

Merrey, D. J. 1986b. Reorganizing irrigation: local level management in the Punjab (Pakistan). Pages 26-43 in D. J. Merrey and J. M. Wolf, editors. Irrigation management in Pakistan: four papers. International Irrigation Management Institute, Digana Village, Sri Lanka. [online] URL: http://publications.iwmi.org/ pdf/H043840.pdf. 
Merrey, D. J. 1986c. The sociology of warabandi: a case study from Pakistan. Pages 44-61 in D. J. Merrey and J. M. Wolf, editors. Irrigation management in Pakistan: four papers. International Irrigation Management Institute, Digana Village, Sri Lanka. [online] URL: http://publications.iwmi.org/pdf/H043841.pdf.

Mittone, L., and M. Ploner. 2011. Peer pressure, social spillovers, and reciprocity: an experimental analysis. Experimental Economics 14(2):203-222. http://dx.doi.org/10.1007/s10683-010-9263-3

Nikiforakis, N., and H.-T. Normann. 2008. A comparative statics analysis of punishment in public-good experiments. Experimental Economics 11(4):358-369. http://dx.doi.org/10.1007/s10683-007-9171-3

North, D. C. 1990. Institutions, institutional change and economic performance. Cambridge University Press, Cambridge, UK. http://dx.doi.org/10.1017/CBO9780511808678

Olson, M. 1993. Dictatorship, democracy, and development. American Political Science Review 87(3):567-576. http://dx.doi. org/10.2307/2938736

Olson, M. 2009. The logic of collective action: public goods and the theory of groups. Harvard University Press, Cambridge, Massachusetts, USA.

Ostrom, E. 1990. Governing the commons: the evolution of institutions for collective action. Cambridge University Press, Cambridge, UK. http://dx.doi.org/10.1017/CBO9780511807763

Ostrom, E. 2009. Understanding institutional diversity. Princeton University Press, Princeton, New Jersey, USA.

Ostrom, E. 2007. A diagnostic approach for going beyond panaceas. Proceedings of the National Academy of Sciences 104 (39):15181-15187. http://dx.doi.org/10.1073/pnas.0702288104

Ostrom, E., and R. Gardner. 1993. Coping with asymmetries in the commons: self-governing irrigation systems can work. Journal of Economic Perspectives 7(4):93-112. http://dx.doi.org/10.1257/ jep.7.4.93

Ostrom, E., J. Walker, and R. Gardner. 1992. Covenants with and without a sword: self-governance is possible. American Political Science Review 86(2):404-417. http://dx.doi.org/10.2307/1964229

Otto, I. M., and F. Wechsung. 2014. The effects of rules and communication in a behavioral irrigation experiment with power asymmetries carried out in North China. Ecological Economics 99:10-20. http://dx.doi.org/10.1016/j.ecolecon.2013.12.007

Palfrey, T. R., and J. E. Prisbrey. 1997. Anomalous behavior in public goods experiments: How much and why? American Economic Review 87:829-846. [online] URL: http://www.jstor.org/ stable/2951327.

Panagopoulos, C. 2010. Affect, social pressure and prosocial motivation: field experimental evidence of the mobilizing effects of pride, shame and publicizing voting behavior. Political Behavior 32(3):369-386. http://dx.doi.org/10.1007/s11109-010-9114-0

Possehl, G. L. 2002. The Indus civilization: a contemporary perspective. Altamira, Oxford, UK.

Rege, M., and K. Telle. 2004. The impact of social approval and framing on cooperation in public good situations. Journal of Public Economics 88(7-8):1625-1644. http://dx.doi.org/10.1016/ $\underline{\mathrm{S} 0047-2727(03) 00021-5}$
Sally, D. 1995. Conversation and cooperation in social dilemmas: a meta-analysis of experiments from 1958 to 1992. Rationality and Society 7(1):58-92. http://dx.doi.org/10.1177/1043463195007001004

Sarker, A., and T. Itoh. 2001. Design principles in long-enduring institutions of Japanese irrigation common-pool resources. Agricultural Water Management 48(2):89-102. http://dx.doi. org/10.1016/S0378-3774(00)00125-6

Scott, A. 1955. The fishery: the objectives of sole ownership. Journal of Political Economy 63(2):116-124. http://dx.doi. org/10.1086/257653

Singleton, S., and M. Taylor. 1992. Common property, collective action and community. Journal of Theoretical Politics 4 (3):309-324. http://dx.doi.org/10.1177/0951692892004003004

Smith, A. 1759. The theory of moral sentiments. Printed for A. Millar, London, UK.

Smith, A. [1789] 2004. Theorie der ethischen Gefühle. [Theory of ethic feelings]. Felix Meiner Verlag, Hamburg, Germany.

Soetevent, A. R. 2005. Anonymity in giving in a natural context - a field experiment in 30 churches. Journal of Public Economics 89(11-12):2301-2323. http://dx.doi.org/10.1016/j.jpubeco.2004.11.002

Tang, S. Y. 1992. Institutions and collective action: self-governance in irrigation. ICS Press, San Francisco, California, USA.

Trawick, P. 2001. The moral economy of water: equity and antiquity in the Andean commons. American Anthropologist 103 (2):361-379. http://dx.doi.org/10.1525/aa.2001.103.2.361

Vollan, B. 2008. Socio-ecological explanations for crowding-out effects from economic field experiments in southern Africa. Ecological Economics 67(4):560-573. http://dx.doi.org/10.1016/j. ecolecon.2008.01.015

Wescoat, J. L. Jr., S. J. Halvorson, and D. Mustafa. 2000. Water management in the Indus basin of Pakistan: a half-century perspective. International Journal of Water Resources Development 16(3):391-406. http://dx.doi.org/10.1080/713672507

Wheeler, M. 1968. The Indus civilization. Third edition. Cambridge University Press, Cambridge, UK.

Wittfogel, K. A. 1981. Oriental despotism: a comparative study of total power. Vintage, New York, New York, USA.

World Bank. 2004. Accelerated development of water resources and irrigated agriculture of Pakistan. World Bank, Washington, D.C., USA. [online] URL: http://www-wds.worldbank.org/ external/default/WDSContentServer/WDSP/IB/2004/02/06/000090341 20040206114019/Rendered/PDF/256651PK0vol0II.pdf.

World Bank. 2005. Pakistan: country water resources assistance strategy: water economy: running dry. World Bank, Washington, D.C., USA. [online] URL: http://www-wds.worldbank.org/ external/default/WDSContentServer/WDSP/IB/2005/12/21/000160016 20051221165623/Rendered/PDF/340810PK.pdf.

Zelmer, J. 2003. Linear public goods experiments: a meta-analysis. Experimental Economics 6(3):299-310. http://dx.doi.org/10.1023/ A:1026277420119 


\section{APPENDIX 1}

\section{Socio-economic attributes of the sample population}

Table A1.1. Summary statistics

\begin{tabular}{lcc}
\hline Variable & Mean & Standard deviation \\
\hline Age & 41.04 years & 14.35616 \\
Age (elders) & 70.125 & 5.24 \\
Household size & 7.7 people & 3.67 \\
Size of landholdings & 13.0 acres & 14.96 \\
\hline
\end{tabular}

Table A1.2. Detailed Summary statistics of socio-economic conditions of participants

\begin{tabular}{lcllll}
\hline Household assets & & Education level & \multicolumn{3}{l}{ Landholdings (type) } \\
\hline television & $83.00 \%$ & None & $14.77 \%$ & Freehold & $85.37 \%$ \\
refrigerator & $69.30 \%$ & Some primary & $9.66 \%$ & Leasehold & $11.59 \%$ \\
air conditioner & $8.44 \%$ & Primary school & $12.5 \%$ & No title & $3.05 \%$ \\
washing & $58.60 \%$ & Secondary school & $50.57 \%$ & & \\
machine & & Technical & $3.98 \%$ & & \\
& & University & $8.52 \%$ & & \\
\hline Income sources & & Transport ownership & & Marital Status & \\
\hline Cultivation & $85.8 \%$ & Car & $17.61 \%$ & Married & $77.84 \%$ \\
Livestock & $60.8 \%$ & Motor-cycle & $59.09 \%$ & Single & $17.05 \%$ \\
Employment & $8.52 \%$ & Bicycle & $57.39 \%$ & Widowed & $5.11 \%$ \\
Private business & $5.68 \%$ & None & $8.52 \%$ & & \\
\hline Own private tube well & Share cropping & & & \\
\hline Yes & $43.58 \%$ & Yes & $19.89 \%$ & & \\
No & $56.42 \%$ & No & $80.11 \%$ & & \\
\hline
\end{tabular}


Table A1.3. Summary statistics of villages

\begin{tabular}{lcc}
\hline Variable & Mean & Standard deviation \\
\hline HH population & 473.625 & 100.9745 \\
Market access & 20.625 & 10.24774 \\
Water disputes village & 5.791667 & 2.12132 \\
\hline
\end{tabular}




\section{APPENDIX 2}

Experiment Protocol

\section{Experiment Place}

Experiments were carried out in coordination with agriculture field staff at places which are used by field staff for their regular interaction with farmers. Generally the gathering place was a dera, it is a facility maintained and owned by large farmers. Importantly this is also the place where community leaders/elders meet to discuss general matters of concern including water disputes.

\section{Choosing experiment participants}

In general three methods were used to gather people for a meeting:

- Announcements from Mosque's loudspeaker

- Cell phone messages.

- Word of mouth

In order to choose participants:

- See who is able to understand the experiments clearly by using quizzes

Experiments are to be conducted in groups of 5 with some groups having additional member acting as a leader/elder.

\section{General instruction to the participants}

\section{Introduction}

This is a research exercise to understand how farmers manage irrigation systems in this area. We are going to conduct an experiment. Each person who takes part in the experiment gets Rs. 60 for just participation. You can earn more during the course of experiment. The money you earn during the experiment comes from a foreign university. The questionnaire and other data collected during the course of this experiment would only be used for research purposes; no part of this data will be available to any government agency. You should listen to the instructions very carefully and ask questions at any point. We will conduct short quizzes to see if you understand the experiment. You can only participate in the experiment when you fully understand it.

\section{Experiment Design}

This experiment is based on the real-life scenarios encountered in decision-making with regards to irrigation. 
$>$ At the start two people are chosen as elders. The criterion for their selection is age of the participants. The most aged person is best suited to the role.

\section{Step 1: All other participants are randomly divided into groups of 5.}

- In the game these people represent one village sharing a watercourse with discharge capacity of 2 cusec $^{1}$.

Also you should know that in the game:

- Each player has 1 acre $^{2}$ of land which they need to irrigate in order to enhance their crop productivity.

- All players are growing the same crops.

Step2: Within the group each member is randomly assigned a unique position (1, $2,3,4$ and 5) by drawing a concealed card.

The players are called player 1, player 2 etc. (corresponding to their position). During the experiment members of each group as well as the position of these players remain fixed.

\section{Baseline experiment}

During the baseline scenario each player has to make two separate decisions. At the time of making these decisions each player acts independently without consulting anyone else. Players are not allowed to talk to each other or say anything in public during the baseline rounds. To ensure that you can make decisions independently, players in the same group are to be seated in such a way that no one is able to see other player's decision.

\section{Investment Decision}

\section{Step 1: All players (except elders) are provided with an initial endowment (10} tokens).

Each token represents .80 PKR.

Step 2: Decide how much of this endowment you want to invest in the maintenance of irrigation infrastructure.

- Everyone writes the amount they want to invest on the piece of paper (decision card) provided to you. You will be asked to hand over this paper to the facilitator after you have made your decision.

1 Cusec $=$ cubic feet per second; 1 Cusec $=28.317$ litres per second

21 acre $=0.40468564224$ hectare 
All individuals make their decision simultaneously and independently without consulting other members of the group. You should remember that a fixed amount of water (max. 200 minutes per turn) is discharged from the main canal to your watercourse (discharge-rate of 2 cusec). As in real life this amount is relevant for one turn only.

The amount of water available for participants to irrigate their fields depends upon their collective level of investment. Investment in the maintenance of the watercourse means that less water is wasted. The collective investment for a group is calculated by adding the individual investment of each group member. If in a given round the collective investment is less than 20 tokens then all the water entitled to the group in that round is wasted. Table 1 shows the relationship between group investment and amount of water available (Table 1 is shown by the facilitators).

After investment decision has been made by all group members facilitators publicly announce the amount invested by each player as well as the collective group investment and amount of water available to the group for irrigation.

Table A.6.1. Investment and CPR

\begin{tabular}{|l|l|}
\hline Total token investment & $\begin{array}{l}\text { Water available for the group (number of } \\
\text { minutes) }\end{array}$ \\
\hline$<20$ & 0 \\
\hline 20 & 5 \\
\hline 21 & 5 \\
\hline 22 & 10 \\
\hline 23 & 15 \\
\hline 24 & 20 \\
\hline 25 & 30 \\
\hline 26 & 40 \\
\hline 27 & 50 \\
\hline 28 & 65 \\
\hline 29 & 85 \\
\hline 30 & 100 \\
\hline 31 & 115 \\
\hline 32 & 130 \\
\hline
\end{tabular}




\begin{tabular}{|c|c|}
\hline 33 & 145 \\
\hline 34 & 155 \\
\hline 35 & 165 \\
\hline 36 & 170 \\
\hline 37 & 180 \\
\hline 38 & 185 \\
\hline 39 & 185 \\
\hline 40 & 190 \\
\hline 41 & 190 \\
\hline 42 & 195 \\
\hline 43 & 195 \\
\hline 44 & 195 \\
\hline 45 & 195 \\
\hline 46 & 200 \\
\hline 47 & 200 \\
\hline 48 & 200 \\
\hline 49 & 200 \\
\hline 50 & 200 \\
\hline
\end{tabular}

\section{Extraction Decision}

Step 1: Each player decides how much water to take from the total amount available for irrigating his field.

- Players decide about the duration of time the tap to their individual field is open. Players are allowed to choose any multiple of 5 between 0 and 50 (minutes).

The decisions are made sequentially which means that the player who is assigned position 1 (player1) makes the decision first, and then player 2 does the same and so on. 
The water available for player 2 depends upon player1's decision. Similarly the water available for player 3 depends upon the extraction decision of players 1 and 2. The process is repeated for rest of the players.

Consider this example: If the total amount of water available is 180 minutes, then first player 1 decides how much to take from this. If player 1 decides to extract water for 50 minutes then the amount of water available to player 2 is 130 (180 - 50), so player 2 has to decide how much to take from this amount. If player 2 decides to extract water for 50 minutes then the amount of water available for player 3 is 80 minutes(130 - 50). Player 3 has to decide how much water to take from these 80 minutes. If player 3 decides to take water for 40 minutes then the amount available to player 4 is 40 minutes $(80-40)$. So player 4 has to decide how much water to take from this 40 minutes, if player 4 decides to extract water for 40 minutes then no water is available for player 5 (40-40).

All individual decisions are made transparent to all other players at the end of the round. Each player knows how much others invested in the first step of the experiment and how much water they took in the second step.

Pay-offs

Earnings consist of two parts:

1. Tokens which were not invested in the investment step of the experiment are kept in the individual's savings account.

2. Tokens earned from utilizing water.

Total earnings $=$ Tokens not invested $($ savings $)+$ tokens earned from utilizing water .

The amount of water taken (time) determines the amount of tokens earned in each round. Table 3 shows the relationship between amount of water utilized and tokens earned. If for example a player decides to take water for 25 minutes he earns 10 tokens. Table 3 is shown and explained to the experiment participants.

Table A.6.2. Pay-offs

\begin{tabular}{|l|l|}
\hline No. of minutes & Tokens earned \\
\hline 0 & 0 \\
\hline 5 & 0 \\
\hline 10 & 0 \\
\hline 15 & 1
\end{tabular}




\begin{tabular}{|l|l|}
\hline 20 & 4 \\
\hline 25 & 10 \\
\hline 30 & 15 \\
\hline 35 & 18 \\
\hline 40 & 19 \\
\hline 45 & 19 \\
\hline 50 & 20 \\
\hline
\end{tabular}

Question 1: If a group invests a total of 45 tokens, what amount of water would be available to that group?

A: 100 B: 160 C: 185 D: 195 E: 200

Question 2: If two participants invest 10 tokens each and the three other participants invest 5 tokens each, what will be the total amount of water available that group?
A: 0
B: 65
C: 115 D: 165
E: 200

Question 3: If total amount of water available to group is 100 gallons/turn and you extract water for 40 minutes how much water is left for the rest of the group?
A: 0
B: 100 C: 20
D: 60
E: 80

Question 4: If you extract water for 40 minutes how many tokens do you earn from extracting this amount of water (only the token earned from utilizing water not the total earnings)?
A: 0
B: 6
C: 15
D: 19
E: 20

Question 5: If you invest 5 tokens and extract water for 20 minutes, how many total tokens do you earn?
A: 0
B: 4
C: 9
D: 13
E: 18

\section{Treatment Stage}

Now we come to the second part of experiment where different treatments are introduced. 


\section{Treatment A: Communication}

$>$ The first two stages are the same as in the baseline rounds; players first make investment decision and then extraction decision. A third stage is added after all players have made their extraction decisions. In this stage all players are asked to decide simultaneously whether they want to use treatment A (Communication) and if yes against which player(s).

- Each player is given the sheet "Treatment Decision Card".

- Players are asked to write their decision on the card provided by the facilitator. Here you first need to indicate whether you want to use the treatment or not, after that you have to write against which players you want to use the treatment.

Treatment A allows player to talk with other player(s). Players who opt for this treatment are given fixed amount of time (3-4 minutes per time slot) to talk to other group member(s). The experimenter will make sure that everyone remains within these time limits.

- In order to use this treatment a player endures a fixed cost (1 token per time slot).

- In one treatment session the initiator can invite more than one player. Consider for example player 5 if he wants to use this treatment, first he needs to write "yes" in the box "treatment decision" to indicate his intention, then he needs to write against whom (which players) he wants to use this treatment. Say he wants to use this treatment against player 1,2 and 3. So he writes the position number of these players (1, 2 and 3) on the "treatment decision" sheet. Having more than one player in a treatment session does not raise the cost of treatment session. In a given treatment session initiator can have as many players as he likes.

- A player can get more than one time slots. If for example player 2 wants to have detailed discussion and thinks that one time slot is not enough, or if he wants to have different treatment sessions for different players, he can get more than one time slot. However he needs to indicate this at the same time as his treatment decision. Also he has to indicate the players against whom he wants to initiate each of these treatment sessions separately even if all the players are same for both sessions. A player should also remember that each treatment slot has its own fixed costs; so one time slot costs 1 token, 2 time slots cost 2 tokens and so on.

$>$ If more than one player wants to talk to the same player then preference is given to tail-end players. This means that initially requests of tail-users are fulfilled before moving onto head-users. Consider for example that both player 5 and player 2 indicate that they want to talk to player 1 , in such a case player 5 will talk to player 1 first, and only after the completion of player 5's time slot player 2 will be able to talk to player 1. 
$>$ It must be noted that treatments cannot be used to change the actions already taken before or even during the round in which treatment was initiated. Only possible effects of treatment are for future rounds.

Question 6: Is the communication option free?
A: Yes
B: No

Question 7: How much does one communication session (one time slot) costs?
A: 0
B: 1
C: 2
D: 3

Question 8: How many players can you talk to during one time slot?
A: None
B: 1
C: 2
D: As many as I like

\section{Treatment B: Traditional leaders}

The first two stages of are the same as in the baseline rounds; players first make investment decision and then extraction decision. A third stage is added after all players have made their extraction decision. In this stage all players are asked to decide simultaneously whether they want to use treatment B (Traditional leaders) and against which player(s).

- Each player is given the sheet "Treatment Decision Card".

- Players are asked to write their decision on the card provided by the facilitator. Here you need to first indicate whether you want to use the treatment or not, after that you have to write against whom (which players) you want to use the treatment.

Treatment B allows players to take the player(s) of their choosing to a traditional authority represented by an elder.

- These leaders were selected at the start of the experiment. In all cases, efforts were made to call actual leaders/elders for the role of the elder. However in cases of their unavailability, the most aged person was chosen to act as the elder. During the baseline phase of the experiments, these elders/leaders were kept in a different room. Also, before the treatment phase, the elders did not know which group they were going to be placed in.

- A traditional leader invites all the players. He first allows the player(s) who has initiated the treatment to present his case (max. 1 min to one person) after that the player against whom treatment is initiated is given a chance to speak. It is the responsibility of an elder to conduct a treatment session so he has full authority over how to proceed in a given session. 
- The elder acts as a mediator between these parties to resolve their differences. During the treatment session elder can interrupt at any stage, he can also facilitate in obtaining non-binding commitments from any one of parties involved. Traditional leaders/elders can also enforce informal sanctions such as disapproval of behavior, public embarrassment of offenders, demanding public apology or commitment/promise. It must be noted that all actions as well as demands of leaders are non-binding for participants. Elders do not take part in the provision or the extraction part of the experiment.

- In order to initiate this option players endure fixed costs (1 token per session).

- A discussion session is limited to maximum of 3 to 5 minutes depending upon the number of initiators. The experimenter will make sure that everyone remains within these time limits.

- One player can initiate more than one treatment sessions; however these treatments have to be against different players. In the context of this treatment it means that a player can initiate only one treatment session against another player in a given round. So for example if player 2 initiates a treatment session against player 5, player 2 has to complete whatever he wants to talk about player 5 in this session as he will not get another opportunity to raise these concerns in this particular round.

If you want to use this treatment for more than one player you need to write the player number in separate boxes in the section marked "players".

- For example consider you are player 5 and you want to use this treatment for player 1 and player 3, then you should first write "yes" in the box treatment decision. After that you should write player numbers in the next box. In this section there are four separate boxes. For using this treatment against two players (player1 and player 3) first write 1 in the first box and then write 3 in the second box.

- You should remember that one discussion session is against only one other group member. This means that if you want to initiate this treatment against two players you should get two discussion sessions. However this also means that your costs would be doubled. So without any sharing of costs one time slot costs 1 token, 2 time slots cost 2 tokens and so on.

- If more than one player decides to use this treatment against the same player in the same round then they share the costs of this discussion session. So consider if player 5, player 4 and player 2 indicate that they want to use this treatment against player 1 then these player share the costs of the same discussion session against player 1. In this (combined) discussion session each initiator (player 5, 4 and 2 in this case) is given the opportunity to raise his concerns. The maximum amount of time available to each initiator is one minute however this is flexible depending 
upon the discretion of elder. A discussion session can go on for a maximum of 5 minutes. Cost for each player in this case is $1 / 3$ tokens ( 1 token/number of initiators).

- First preference is given to the issues encountered by tail-users. Consider for example that player 5 , player 4 and player 2 indicate that they want to use this treatment against player 1 , then in the discussion session leader will first ask player 5 to talk then after him player 4 and after him player 2 can raise their concerns. The player against whom the treatment is initiated may be allowed to talk depending upon the discretion of the leader.

The issues of tail-users are prioritized which means that treatment session initiated by tail-users are conducted first. Consider for example if player 5 initiates this treatment against player 3 while player 2 and player 3 initiate the treatment against player 1 then in this case first discussion will be against player 3, only after completion of this discussion other sessions can begin.

$>$ It must be noted that treatments cannot be used to change the actions already taken before or during the round in which treatment is initiated. Only possible effects of treatment are for future rounds.

Question 6: Is the traditional leadership option free?
A: Yes
B: No

Question 7: How much does intervention by traditional leaders cost if you use it against two other group members without any sharing of costs?
A: 0
B: 1
$\mathrm{C}: 2$
D: 3

Question 8: Say you are player 5 and you initiated a discussion session against player 4. Can you discuss your problems about player 2 in this session?
A: Yes
B: No

Question 9: If you want to initiate a discussion session against all other group members how many discussion sessions you should get?
A: 1
B: 2
C: 3
D: 4

Question 10: If two players initiate a treatment session for the same player in the same round how much each one of them has to pay individually?
A: 1
B: $1 / 2$
$\mathrm{C}: 1 / 3$ 


\section{Treatment C: Third-party Punishment}

$>$ The first two stages are the same as in the baseline rounds i.e. players first make investment decision and then extraction decision. A third stage is added after all players have made their extraction decision. In this stage all players are asked simultaneously to decide whether they want to use treatment $\mathrm{C}$ (Third-party punishment) and against which player(s).

- Each player is given the sheet "Treatment Decision Card".

- Players are asked to write their decision on the card provided by the assistants. Here you need to first indicate whether you want to use the treatment or not, after that you have to write against which players you want to use the treatment.

Treatment $\mathrm{C}$ allows players to punish other player(s). They can report to the "water committee" which is represented by the experiment facilitator. With a probability of $2 / 3$ the facilitator will punish the person against whom the treatment was initiated. Whether the punished player pays the fine or not is decided by drawing out cards. Punishment amount payable is 4 tokens. It must be remembered that these 4 tokens are subtracted from the earnings of the punished player; however these 4 tokens are not given to the player who initiated the punishment. For the player who initiated the treatment there is no direct monetary benefit attached to the punishment.

- One player can initiate more than one treatment session; however these treatments need to be against different players. It means that in a given round a player can only invoke punishment once against another player. Consider for example player 4 , if desired he can initiate this treatment against multiple players at the end of a round. However he cannot initiate this treatment twice against the same player in the same round.

If you want to use this treatment against more than one player you need to write the player number in separate boxes in the section marked "players".

- For example consider you are player 5 and you want to use this treatment against player 1 and player 3 then you should first write "yes" in the box treatment decision. After that you should write player numbers in the next box. In this section you can see four separate boxes. For using the treatment against two players (player 1 and player 3) first write 1 in the first box and then write 3 in the second box.

Punishment treatment has a fixed cost (1 token per punishment session) for those who initiate this process.

- If you want to initiate this treatment against two players then you would have to pay 2 tokens, for three players you have to pay 3 tokens etc. 
$\circ$ If more than one player initiates this treatment against the same player then they share the costs. Consider for example if both player 5 and player 2 want to initiate punishment treatment against player 4 then they will share the costs, which means that each player pays $1 / 2$ token (1 token / total number of initiators).

$>$ The issues of tail-users are addressed first. For example if player 4 wants to use treatment against player 1 while player 2 wants to use treatment against player 3 then first punishment treatment against player 1 is completed before moving onto others.

Question 6: Is the punishment option free?
A: Yes
B: No

Question 7: How much does punishment cost if you use it against two other group members without any sharing of costs?
A: 0
B: 1
C: 2
D: 3

Question 8: What are the chances of a player getting not fined once a punishment option has been initiated against him?
A: 1
B: $1 / 2$
$\mathrm{C}: 1 / 3$
D: No chance

Question 9: Once I am subject to punishment treatment how many tokens do I need to pay as a fine in this round?
A: 0
B: 1
C: 3
D: 4

Question 10: If two players initiate a treatment session for the same player in the same round how much each one of them has to pay individually?
A: 1
B: $1 / 2$
C: $1 / 3$

\section{Treatment D: Mixed}

The first two stages are the same as in the baseline rounds; players first make investment decision and then extraction decision. A third stage is added after all players have made their extraction decision. In this stage all players are asked simultaneously to decide whether they want to use treatment $\mathrm{A}, \mathrm{B}$, or $\mathrm{C}$ (communication, traditional authority, punishment respectively) and against which player(s).

- Each player is given the sheet "Treatment Decision Card".

- Players are asked to write their decision on the card provided by the assistants. Here you need to first indicate whether you want to use the treatment or not, after that you have to write against which players you want to use the treatment. 
For treatment $\mathrm{D}$ each player has the option to choose between different mechanisms; a player can choose either to communicate with other players (A) or involve traditional authorities (B) or use third-party punishments (C). Each option has the same fixed costs (1 token per person).

- You should indicate which treatment you want to choose in the box "Treatment" on the treatment decision sheet.

If you want to use treatment against more than one player then:

- In case you want to use the same treatment against two or more players then write the round number in the first section, "Yes" in the second section, name of the treatment you want to use in the third section and indicate the player's number (against whom you want to use this treatment) in separate columns.

- In case you want to use different treatments against different players then add another entry in the row beneath the original one. Both rows should have the same round number. Rest of the process is same.

- You cannot use more than one treatment against the same player in the same round.

Question 6: How much does a communication session cost if you use it against two other group members?
A: 0
B: 1
$\mathrm{C}: 2$
D: 3

Question 7: How much does a traditional authority session cost if you use it against two other group members?
A: 0
B: 1
$\mathrm{C}: 2$
D: 3

Question 8: How much does a punishment treatment cost if you use it against two other group members?
A: 0
B: 1
C: 2
D: 3

Question 9: Can you choose one treatment for one player and a different treatment for other players in one round?
A: Yes
B: No

Question 10: Can you choose different treatments for one player in the same round?
A: Yes
B: No 


\section{APPENDIX 3}

Player position, Treatments and Investment \& Extraction levels

Table A3.1. p-values of two-tailed Wilcoxon Matched-Pairs Signed-Ranks Test statistics for the number of tokens invested for the provision of CPR by players at different positions during the baseline phase of the experiment (32 observations for each position).

Table A3.2. p-values of two-tailed Wilcoxon Matched-Pairs Signed-Ranks Test statistics for

\begin{tabular}{lcccc}
\hline & Player 2 & Player 3 & Player 4 & Player 5 \\
\hline Player 1 & 0.9925 & 0.0667 & 0.4431 & 0.6875 \\
Player 2 & - & 0.2169 & 0.8224 & 0.779 \\
Player 3 & - & - & 0.1471 & 0.1298 \\
Player 4 & - & - & - & 0.9701 \\
\hline
\end{tabular}

extraction by players at different positions during the baseline phase of the experiment (32 observations for each position).

\begin{tabular}{|c|c|c|c|c|}
\hline & Player 2 & Player 3 & Player 4 & Player 5 \\
\hline Player 1 & 0.7364 & 0.0185 & 0.0093 & 0.0001 \\
\hline Player 2 & & 0.0942 & 0.0031 & 0.0002 \\
\hline Player 3 & & & 0.1752 & 0.0003 \\
\hline Player 4 & & & & 0.0002 \\
\hline
\end{tabular}

Table A3.3. p-values of Mann-Whitney test results for differences in investments, extraction level and earnings between different treatments during 8 treatment rounds.

\begin{tabular}{lccc}
\hline & Investment & Extraction & Earnings \\
\hline C and TA & 0.4622 & 0.5286 & 0.5995 \\
C and P & 0.1559 & 0.0929 & 0.1152 \\
C and IC & 0.2076 & 0.2936 & 0.1415 \\
TA and P & 0.4622 & 0.3446 & 0.2936 \\
\hline
\end{tabular}




\begin{tabular}{llcc}
\hline TA and IC & 0.5995 & 0.4306 & 0.2936 \\
P and IC & 0.9164 & 0.9164 & 0.9581 \\
\hline
\end{tabular}

Figure A3.1. Share of extraction for players occupying different positions as a function of the total amount of CPR produced.

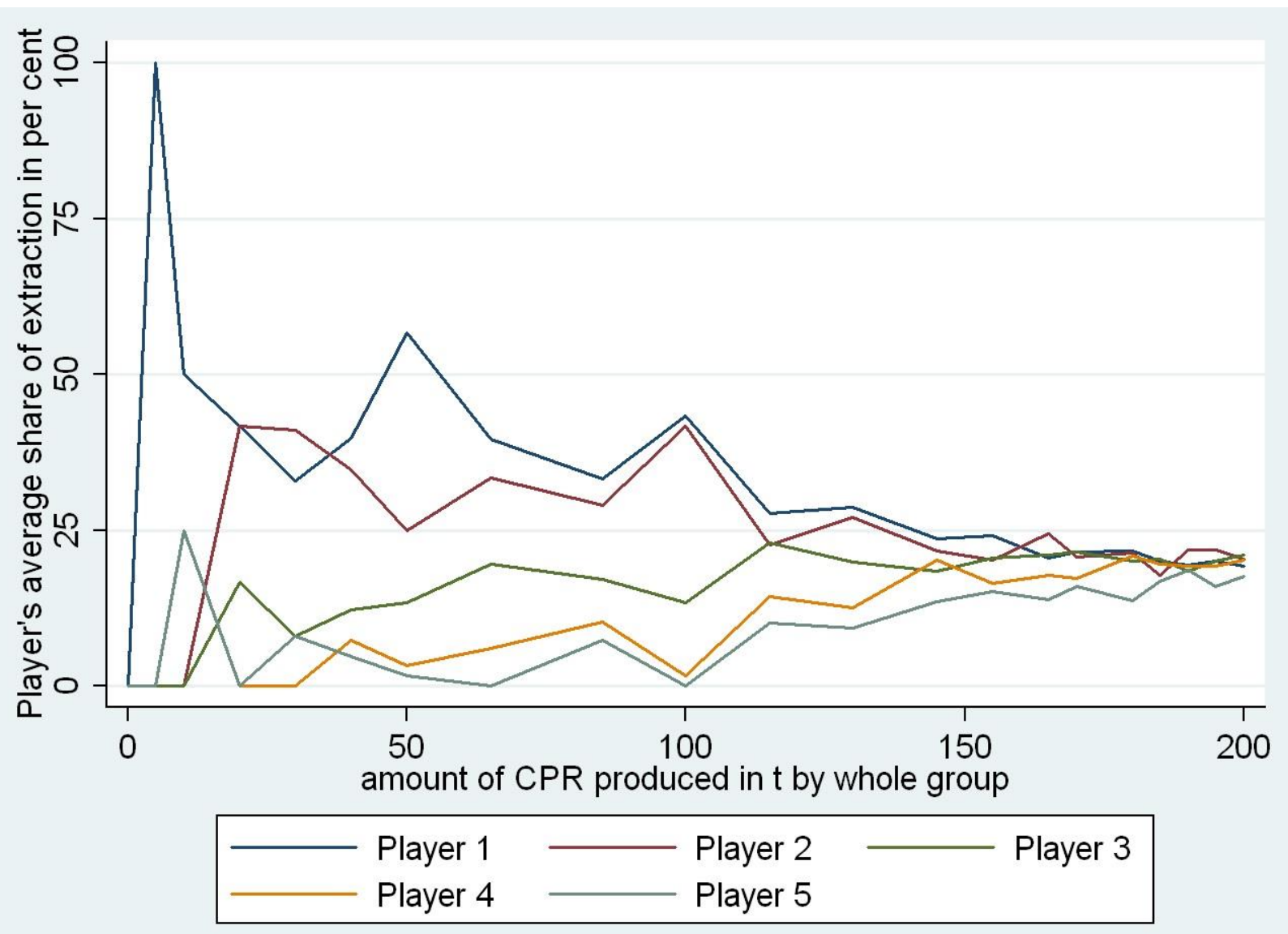




\section{APPENDIX 4}

Detailed Regression models explaining different individual and group decisions

Table A.4 List of variables

Personal Information (Individual level variables)

Education level of the participant $(01=$ No formal education; $02=$ Started school; $03=$

Education level Finished primary school; 04 =finished secondary school; $05=$ Further education

(college/university/ polytechnic)

Age Age of the participant

Size of Land

holdings

The amount of land held by the participants (in Acres)

Member dominant Whether participant belongs to one of the top three influential baradaris of the area (Dummy

Baradari $\quad$ variable $0=$ No \& $1=$ Yes)

Owning private tube Whether the participant owns or has access to water from private tube well (Dummy variable well $\quad 0=$ No \& $1=$ Yes)

Feel accepted in Participants views about whether he feels accepted as part of the village community $(0=$ Don't community $\quad$ know $1=$ Strongly agree; $2=$ Agree ; $3=$ Disagree; $4=$ Strongly Disagree)

Trust index Participants views about his fellow villager's honesty and trustworthiness $(0=$ Don't know $1=$ Strongly agree; $2=$ Agree $; 3=$ Disagree; $4=$ Strongly Disagree)

Group level variables

Network density of social relations

No. of casts in

group

бage

o education level

$\sigma$ size land holding
The relationship status between different group members

number of different castes in the group

Standard deviation of age in the group, meant to capture variation in age between different group members

Standard deviation of education level in the group, meant to capture variation in education between different group members

Standard deviation of land holdings in the group, meant to capture variation in land holdings between different group members

Village level variables

No. of households

Head-or tail-end location

Distance to market

Frequency of water disputes
Population of the village in terms of households

Position of the village along the canal/irrigation system ( $1=$ Head-end $2=$ Middle $3=$ Tail-end $)$

Distance to the nearest major agricultural commodities market (in kilometers)

Average number of water disputes brought to the irrigation officials in the last three years

Game variables 
Position number

Extraction ( $t-1)$

Group Investment

$(t-1)$

Gini-coeff.

Investment ( $t-1)$

Gini-coeff.

Earnings ( $t-1)$

Period

Interaction $C$ \&

treatment phase

Interaction TA \&

treatment phase

Interaction $P$ \&

treatment phase

Interaction IC \&

treatment phase

Received $C$

treatment ( $t$-1)

Received TA

treatment ( $t-1)$

Received $P$

treatment ( $t-1)$

Initiated TA

treatment ( $t-1)$

Initiated $C$

treatment ( $t-1)$

Initiated P treatment Indicates whether or not participant initiated a Punishment Treatment against one or more of $(t-1)$

The position occupied by the player

Amount of water extracted (in minutes) in last round

Number of tokens invested by the group in the last round

Gini-coefficient of investment in the last round. Indicates inequality in investments

Gini-coefficient of Earnings in the last round. Indicates inequality in Earnings

Period is a binary variable. $0=$ Baseline Phase $1=$ Treatment phase

Indicates treatment phase of communication groups

Indicates treatment phase of Traditional authority groups

Indicates treatment phase of external sanction groups

Indicates treatment phase of Institutional choice groups

Indicates whether or not participant received Communication Treatment in the previous round

Indicates whether or not participant received Traditional authority Treatment in the previous round

Indicates whether or not participant received Punishment Treatment in the previous round

Indicates whether or not participant initiated a Traditional authority Treatment against one or more of their group members in the previous round

Indicates whether or not participant initiated a Communication Treatment against one or more of their group members in the previous round

Table A4.1. Mixed-effects regression results of individual amounts invested and earned (coefficients with robust standard errors in parentheses; ${ }^{*} \mathrm{p}<0.1,{ }^{* *} \mathrm{p}<0.05,{ }^{* * *} \mathrm{p}<0.01$ )

\begin{tabular}{lcccc}
\hline & $\begin{array}{c}\text { Investment } \\
\text { (Round 2-18) }\end{array}$ & $\begin{array}{c}\text { Investment } \\
\text { (Round 2-18) }\end{array}$ & $\begin{array}{c}\text { Earnings } \\
\text { (Round 2-18) }\end{array}$ & $\begin{array}{c}\text { Earnings } \\
\text { (Round 2-18) }\end{array}$ \\
\hline \multirow{2}{*}{ Education level } & \multicolumn{2}{c}{ Individual-level variables } & & \\
Age & $-0.0885^{*}$ & -0.0857 & $\mathbf{0 . 1 8 1}^{* *}$ & $\mathbf{0 . 1 6 0}^{* *}$ \\
(R) & $(0.0508)$ & $(0.0530)$ & $\mathbf{( 0 . 0 7 8 3 )}^{*}$ & $\mathbf{( 0 . 0 7 6 1 ) ~}^{*}$ \\
& 0.00687 & 0.00684 & -0.0125 & -0.0127
\end{tabular}


Size of land holdings

Owning private tube well

Member dominant Baradari

Feel accepted in community

Trust index

No. of casts in group

Network density of social relations

Round

1st player position

2nd player position

3rd player position

4th player position

5th player position

Extraction (t-1)

Gini-coeff. earnings (t-1)

Share in investment

Mean extraction except me ( $\mathrm{t}-1)$

Group investment (t-1)

Interaction $\mathrm{C} \&$ treatment phase

Interaction TA \& treatment phase

Interaction P \& treatment phase

Interaction IC \& treatment phase

Received C treatment ( $\mathrm{t}-1)$

Received TA treatment ( $\mathrm{t}-1)$

Received P treatment ( $\mathrm{t}-1)$

\begin{tabular}{cccc}
$(0.0116)$ & $(0.0115)$ & $(0.0137)$ & $(0.0139)$ \\
0.00708 & 0.00690 & -0.00214 & -0.00185 \\
$(0.00936)$ & $(0.00924)$ & $(0.00827)$ & $(0.00824)$ \\
0.0296 & 0.0325 & -0.137 & -0.147 \\
$(0.177)$ & $(0.176)$ & $(0.250)$ & $(0.243)$ \\
0.0190 & 0.0219 & $\mathbf{1 . 2 4 9}$ & $\mathbf{1 . 2 4 8}$ \\
$(0.350)$ & $(0.347)$ & $(\mathbf{0 . 4 7 4})$ & $(\mathbf{0 . 4 7 1})$ \\
-0.0606 & -0.0565 & 0.0109 & 0.0167 \\
$(0.195)$ & $(0.200)$ & $(0.278)$ & $(0.283)$ \\
-0.0264 & -0.0203 & 0.0522 & 0.0332 \\
$(0.270)$ & $(0.267)$ & $(0.347)$ & $(0.348)$ \\
\hline Group variables & & \\
0.0203 & 0.0254 & 0.0416 & 0.0228 \\
$(0.115)$ & $(0.116)$ & $(0.303)$ & $(0.294)$ \\
0.0834 & 0.0879 & -0.00640 & -0.0314 \\
$(0.125)$ & $(0.123)$ & $(0.0656)$ & $(0.0683)$ \\
\hline
\end{tabular}

\begin{tabular}{cccc}
\hline \multicolumn{4}{l}{ Game variables } \\
0.0103 & 0.0127 & $\mathbf{0 . 1 6 0}$ & $\mathbf{0 . 1 5 7 ^ { * * }}$ \\
$(0.0191)$ & $(0.0174)$ & $(\mathbf{0 . 0 6 5 5})$ & $\mathbf{( 0 . 0 6 6 3 )}$
\end{tabular}

$\begin{array}{cccc}- & - & - & - \\ 0.0119 & 0.0170 & -0.536 & -0.514 \\ (0.336) & (0.335) & (0.508) & (0.514)\end{array}$

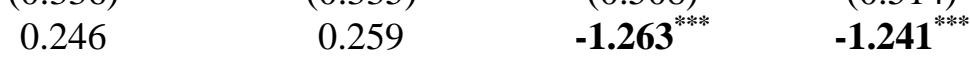

$\begin{array}{llll}(0.349) & (0.355) & (\mathbf{0 . 4 4 2}) & \mathbf{( 0 . 4 3 0})\end{array}$

$\begin{array}{llll}-0.341 & -0.320 & -1.267^{*} & -1.259^{*}\end{array}$

$\begin{array}{llll}(0.392) & (0.399) & (0.766) & (0.764)\end{array}$

$\begin{array}{llll}-0.0455 & -0.0282 & \mathbf{- 3 . 2 2 9}^{* * *} & \mathbf{- 3 . 2 5 0}^{* * * *}\end{array}$

$\begin{array}{llll}(0.333) & (0.340) & \mathbf{( 1 . 0 0 7 )} & \mathbf{( 0 . 9 9 7 )}\end{array}$

$\begin{array}{cccc}-0.0232^{* * * *} & -0.0233^{* * * *} & 0.119 * * * & 0.119\end{array}$

$\begin{array}{llll}(\mathbf{0 . 0 0 6 4 7}) & \mathbf{( 0 . 0 0 6 5 8}) & \mathbf{( 0 . 0 1 8 5}) & \mathbf{( 0 . 0 1 8 8})\end{array}$

$\begin{array}{llll}-1.669^{*} & -1.569 & -4.086 & -4.671\end{array}$

$(0.933) \quad(0.975)$

(2.854) (3.015)

$-13.64 * * * \quad-13.49 * * *$

(3.079) (2.979)

$-0.0865 * * * \quad-0.0915 * * *$

(0.0302) (0.0326)

$\begin{array}{cccc}\mathbf{0 . 0 7 4 6}^{* * * *} & \mathbf{0 . 0 7 6 0} & & \\ (\mathbf{0 . 0 1 5 4}) & (\mathbf{0 . 0 1 6 *}) & & \\ 0.0701 & -0.0565 & -0.639 & -0.686 \\ (0.372) & (0.334) & (1.070) & (1.037) \\ 0.0221 & -0.0223 & -0.226 & -0.389 \\ (0.328) & (0.305) & (0.902) & (0.871) \\ -0.291 & -0.211 & \mathbf{- 1 . 7 9 8} & \mathbf{- 2 . 1 5 4}{ }^{* *} \\ (0.445) & (0.435) & \mathbf{( 1 . 0 3 8 )} & \mathbf{( 1 . 0 4 0 )} \\ -0.147 & -0.154 & -1.032 & -1.250 \\ (0.228) & (0.219) & (0.874) & (0.901) \\ & \mathbf{0 . 6 9 4}{ }^{* *} & & 0.0171 \\ & (\mathbf{0 . 2 8 4 )} & & (0.616) \\ & -0.0290 & & 1.066 \\ & (0.373) & & (0.789) \\ & -0.112 & & 0.475\end{array}$




\begin{tabular}{|c|c|c|c|c|}
\hline \multirow{3}{*}{ Initiated TA treatment $(\mathrm{t}-1)$} & & $(0.375)$ & & $(0.634)$ \\
\hline & & 0.406 & & 0.786 \\
\hline & & $(0.312)$ & & $(1.096)$ \\
\hline \multirow[t]{2}{*}{ Initiated $\mathrm{C}$ treatment $(\mathrm{t}-1)$} & & 0.173 & & 0.553 \\
\hline & & $(0.345)$ & & (1.139) \\
\hline \multicolumn{2}{|l|}{ Initiated $\mathrm{P}$ treatment $(\mathrm{t}-1)$} & -0.628 & & $2.269^{* * * *}$ \\
\hline \multirow{3}{*}{ Constant } & & $(0.638)$ & & $(0.879)$ \\
\hline & $5.445^{* * *}$ & $5.308^{* * * *}$ & $17.54^{* * *}$ & $17.98^{* * * *}$ \\
\hline & $(\mathbf{1 . 1 2 4})$ & $(\mathbf{1 . 1 3 6 )}$ & $(\mathbf{1 . 1 6 7 )}$ & (1.178) \\
\hline \multicolumn{5}{|l|}{ Random-effects Parameters } \\
\hline \multirow{2}{*}{ Village } & -14.83 & -16.55 & -13.06 & -16.21 \\
\hline & $(124.2)$ & $(103.3)$ & $(126.7)$ & $(85.38)$ \\
\hline \multirow{2}{*}{ Group } & $-0.507^{* * * *}$ & $-0.514^{* *}$ & $0.562^{* * * *}$ & 0.577 \\
\hline & $(0.159)$ & $(0.257)$ & $(0.209)$ & $(0.470)$ \\
\hline \multirow{2}{*}{ Residual } & $0.840^{* * * *}$ & $0.838^{* * * *}$ & $1.829^{* * *}$ & $1.827^{* * * *}$ \\
\hline & $(0.0568)$ & $(\mathbf{0 . 0 5 8 3 )}$ & $(0.0599)$ & $(0.0743)$ \\
\hline No. of players & 160 & 160 & 160 & 160 \\
\hline No. of observations & 2410 & 2410 & 2410 & 2410 \\
\hline
\end{tabular}

Table A4.2. Mixed-effects regression models explaining the tokens invested for provision of CPR by player position over all experiment rounds (coefficients with robust standard errors in parentheses; $\left.* \mathrm{p}<0.1,{ }^{*} \mathrm{p}<0.05, * * * \mathrm{p}<0.01\right)$.

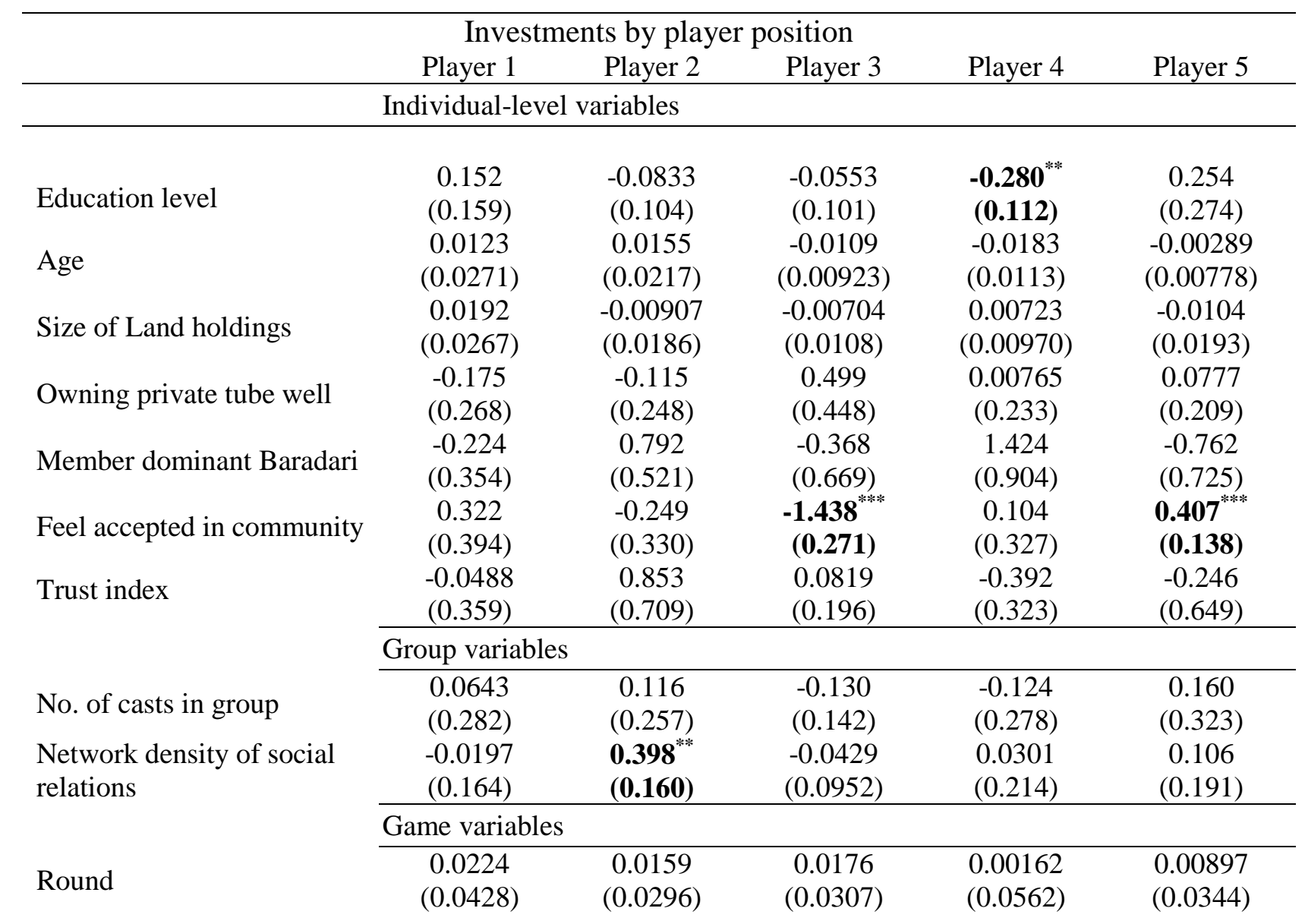




\begin{tabular}{|c|c|c|c|c|c|}
\hline Extraction $(\mathrm{t}-1)$ & $\begin{array}{l}-0.0150 \\
(0.0140)\end{array}$ & $\begin{array}{c}-0.0124 \\
(0.00792)\end{array}$ & $\begin{array}{l}-0.0188 \\
(0.0128)\end{array}$ & $\begin{array}{l}-0.0268^{* * * *} \\
(0.00902)\end{array}$ & $\begin{array}{c}-0.0112 \\
(0.00823)\end{array}$ \\
\hline Group investment (t-1) & $\begin{array}{l}0.0763^{* * * *} \\
(0.0163)\end{array}$ & $\begin{array}{l}0.0953^{* * * *} \\
(0.00967)\end{array}$ & $\begin{array}{l}\mathbf{0 . 0 8 0 3}^{* * * *} \\
(0.0172)\end{array}$ & $\begin{array}{l}\mathbf{0 . 0 7 7 8}^{* * * *} \\
(\mathbf{0 . 0 2 8 1 )}\end{array}$ & $\begin{array}{c}0.0220 \\
(0.0294)\end{array}$ \\
\hline $\begin{array}{l}\text { Gini-coefficient Earnings } \\
(\mathrm{t}-1)\end{array}$ & $\begin{array}{l}-1.036 \\
(1.173)\end{array}$ & $\begin{array}{l}-0.0205 \\
(0.754)\end{array}$ & $\begin{array}{l}0.0799 \\
(1.133)\end{array}$ & $\begin{array}{l}-3.153 \\
(1.968)\end{array}$ & $\begin{array}{l}-3.077 \\
(1.970)\end{array}$ \\
\hline $\begin{array}{l}\text { Interaction } C \& \text { treatment } \\
\text { phase }\end{array}$ & $\begin{array}{c}-0.00326 \\
(0.636)\end{array}$ & $\begin{array}{c}0.229 \\
(0.429)\end{array}$ & $\begin{array}{l}-0.235 \\
(0.255)\end{array}$ & $\begin{array}{l}-0.210 \\
(0.505)\end{array}$ & $\begin{array}{l}0.0450 \\
(0.906)\end{array}$ \\
\hline $\begin{array}{l}\text { Interaction TA \& treatment } \\
\text { phase }\end{array}$ & $\begin{array}{l}-0.341 \\
(0.441)\end{array}$ & $\begin{array}{l}-0.491 \\
(0.353)\end{array}$ & $\begin{array}{l}-0.109 \\
(0.443)\end{array}$ & $\begin{array}{c}0.403 \\
(0.632)\end{array}$ & $\begin{array}{c}0.365 \\
(0.597)\end{array}$ \\
\hline $\begin{array}{l}\text { Interaction P \& treatment } \\
\text { phase }\end{array}$ & $\begin{array}{l}-0.451 \\
(0.700)\end{array}$ & $\begin{array}{c}0.372 \\
(0.625)\end{array}$ & $\begin{array}{l}-0.612 \\
(0.469)\end{array}$ & $\begin{array}{l}-0.358 \\
(0.597)\end{array}$ & $\begin{array}{c}0.310 \\
(0.509)\end{array}$ \\
\hline $\begin{array}{l}\text { Interaction IC \& treatment } \\
\text { phase }\end{array}$ & $\begin{array}{l}-0.292 \\
(0.360)\end{array}$ & $\begin{array}{c}0.323 \\
(0.412)\end{array}$ & $\begin{array}{l}-0.152 \\
(0.343)\end{array}$ & $\begin{array}{l}-0.468 \\
(0.553)\end{array}$ & $\begin{array}{l}-0.150 \\
(0.503)\end{array}$ \\
\hline Received C treatment $(\mathrm{t}-1)$ & $\begin{array}{c}0.420 \\
(0.574)\end{array}$ & $\begin{array}{c}0.167 \\
(0.199)\end{array}$ & $\begin{array}{l}-0.165 \\
(0.354)\end{array}$ & $\begin{array}{c}0.935 \\
(0.572)\end{array}$ & $\begin{array}{c}0.932 \\
(0.616)\end{array}$ \\
\hline $\begin{array}{l}\text { Received TA treatment ( } \mathrm{t}- \\
\text { 1) }\end{array}$ & $\begin{array}{c}0.640 \\
(0.686)\end{array}$ & $\begin{array}{l}-0.372 \\
(0.400)\end{array}$ & $\begin{array}{c}0.189 \\
(0.452)\end{array}$ & $\begin{array}{l}-0.0808 \\
(0.514)\end{array}$ & $\begin{array}{r}-0.0335 \\
(0.649)\end{array}$ \\
\hline Received $\mathrm{P}$ treatment $(\mathrm{t}-1)$ & $\begin{array}{c}0.463 \\
(0.343)\end{array}$ & $\begin{array}{l}-1.089^{*} \\
(0.576)\end{array}$ & $\begin{array}{c}0.308 \\
(0.862)\end{array}$ & $\begin{array}{l}-1.394 \\
(1.379)\end{array}$ & $\begin{array}{r}-0.0645 \\
(0.925)\end{array}$ \\
\hline Initiated TA treatment $(\mathrm{t}-1)$ & $\begin{array}{c}0.824 \\
(1.126)\end{array}$ & $\begin{array}{c}0.798 \\
(0.709)\end{array}$ & $\begin{array}{c}0.202 \\
(0.405)\end{array}$ & $\begin{array}{c}0.447 \\
(0.448)\end{array}$ & $\begin{array}{l}-0.147 \\
(0.759)\end{array}$ \\
\hline Initiated $\mathrm{C}$ treatment $(\mathrm{t}-1)$ & $\begin{array}{l}1.081^{*} \\
(0.639)\end{array}$ & $\begin{array}{c}1.014 \\
(0.705)\end{array}$ & $\begin{array}{c}0.270 \\
(0.678)\end{array}$ & $\begin{array}{l}-1.343 \\
(1.093)\end{array}$ & $\begin{array}{c}0.334 \\
(0.662)\end{array}$ \\
\hline Initiated $\mathrm{P}$ treatment $(\mathrm{t}-1)$ & $\begin{array}{l}0.616 \text { ** } \\
(0.295)\end{array}$ & $\begin{array}{l}-1.596 \\
(1.226)\end{array}$ & $\begin{array}{l}-2.213 \\
(1.596)\end{array}$ & $\begin{array}{c}0.388 \\
(0.717)\end{array}$ & $\begin{array}{l}-0.138 \\
(0.621)\end{array}$ \\
\hline Constant & $\begin{array}{l}3.616 \\
(1.626)\end{array}$ & $\begin{array}{l}1.596 \\
(2.419) \\
\end{array}$ & $\begin{array}{l}8^{8.893}{ }^{* * *} \\
(1.194)\end{array}$ & $\begin{array}{l}6.750 \\
(1.373)\end{array}$ & $\begin{array}{l}6.504^{* * * * *} \\
(1.369)\end{array}$ \\
\hline \multicolumn{6}{|l|}{ Random-effects Parameters } \\
\hline Village & $\begin{array}{c}-19.77 \\
(70.31)\end{array}$ & $\begin{array}{l}-11.33 \\
(78.79)\end{array}$ & $\begin{array}{l}-15.34 \\
(93.26)\end{array}$ & $\begin{array}{c}-19.95 \\
(.)\end{array}$ & $\begin{array}{l}-12.32 \\
(218.1)\end{array}$ \\
\hline Group & $\begin{array}{l}-0.151 \\
(0.248)\end{array}$ & $\begin{array}{c}0.275 \\
(0.198)\end{array}$ & $\begin{array}{l}-0.618 \\
(0.393)\end{array}$ & $\begin{array}{r}-0.0628 \\
(0.200)\end{array}$ & $\begin{array}{r}-0.0371 \\
(0.883)\end{array}$ \\
\hline Residual & $\begin{array}{c}0.723^{* * *} \\
(0.102)\end{array}$ & $\begin{array}{l}0.563^{* * *} \\
(0.0576)\end{array}$ & $\begin{array}{l}0.664^{* * *} \\
(0.186)\end{array}$ & $\begin{array}{l}0.788^{* * *} \\
(0.0826)\end{array}$ & $\begin{array}{c}0.818 \\
(0.735) \\
\end{array}$ \\
\hline No. of players & 32 & 32 & 32 & 32 & 32 \\
\hline No. of observations & 482 & 482 & 482 & 482 & 482 \\
\hline
\end{tabular}

Table A4.3. Mixed effects regression models explaining the total tokens earned from water extraction by player position (coefficients with robust standard errors in parentheses; $* \mathrm{p}<0.1$, $* * \mathrm{p}<0.05, * * * \mathrm{p}<0.01)$.

\begin{tabular}{lccccc}
\hline \multicolumn{7}{c}{ Extraction earnings by player position } \\
\hline \multicolumn{7}{c}{ Player 1 } & Player 2 & Player 3 & Player 4 & Player 5 \\
\hline Individual-level variables & & & & & \\
\hline \multirow{2}{*}{ Education level } & -0.158 & 0.226 & -0.0622 & $\mathbf{0 . 6 0 2}^{* * * *}$ & 0.0149 \\
Age & $(0.202)$ & $(0.312)$ & $(0.199)$ & $\mathbf{( 0 . 1 7 1 )}^{* *}$ & $(0.370)$ \\
& -0.0478 & 0.0121 & -0.0394 & $\mathbf{0 . 0 5 9 4}$ & 0.00986
\end{tabular}




\begin{tabular}{|c|c|c|c|c|c|}
\hline \multirow{3}{*}{ Size of Land holdings } & $(0.0314)$ & $(0.0343)$ & $(0.0242)$ & $(\mathbf{0 . 0 2 0 1})$ & $(0.0280)$ \\
\hline & $0.0855^{*}$ & -0.0572 & 0.0275 & 0.0177 & $0.0431^{*}$ \\
\hline & $(0.0437)$ & $(0.0372)$ & $(0.0380)$ & $(0.0158)$ & $(0.0261)$ \\
\hline \multirow{2}{*}{ Owning private tube well } & -0.256 & 0.113 & -0.507 & 0.126 & -0.119 \\
\hline & $(0.586)$ & $(0.371)$ & $(0.327)$ & $(0.409)$ & $(0.575)$ \\
\hline Member dominant Baradari & $\begin{array}{c}1.510 \\
(1.208)\end{array}$ & $\begin{array}{l}4.225^{* * *} \\
(1.175)\end{array}$ & $\begin{array}{l}-0.305 \\
(1.190)\end{array}$ & $\begin{array}{c}0.278 \\
(0.462)\end{array}$ & $\begin{array}{l}2.435^{* * * *} \\
(0.710)\end{array}$ \\
\hline Feel accepted in community & $\begin{array}{c}0.544 \\
(0.521)\end{array}$ & $\begin{array}{c}0.0634 \\
(0.983)\end{array}$ & $\begin{array}{c}-0.489 \\
(0.583)\end{array}$ & $\begin{array}{l}-0.295 \\
(0.272)\end{array}$ & $\begin{array}{c}-0.552 \\
(0.412)\end{array}$ \\
\hline Trust index & $\begin{array}{l}1.439^{* * *} \\
(0.471)\end{array}$ & $\begin{array}{l}-0.296 \\
(0.783)\end{array}$ & $\begin{array}{l}-0.149 \\
(0.550)\end{array}$ & $\begin{array}{c}-0.957^{* * * *} \\
(\mathbf{0 . 3 3 8})\end{array}$ & $\begin{array}{c}1.739^{*} \\
(0.922)\end{array}$ \\
\hline \multicolumn{6}{|l|}{ Group variables } \\
\hline No. of casts in group & $\begin{array}{c}-0.343 \\
(0.616)\end{array}$ & $\begin{array}{l}0.0270 \\
(0.496)\end{array}$ & $\begin{array}{c}-0.506 \\
(0.328)\end{array}$ & $\begin{array}{c}0.427^{*} \\
(0.220)\end{array}$ & $\begin{array}{c}0.0688 \\
(0.546)\end{array}$ \\
\hline Network density of social relations & $\begin{array}{r}0.0325 \\
(0.260)\end{array}$ & $\begin{array}{l}-0.507 \\
(0.691)\end{array}$ & $\begin{array}{c}-\mathbf{0 . 8 8 9} \\
(\mathbf{0 . 2 0 8})\end{array}$ & $\begin{array}{r}0.0999 \\
(0.507)\end{array}$ & $\begin{array}{l}-0.131 \\
(0.391)\end{array}$ \\
\hline \multicolumn{6}{|l|}{ Game variables } \\
\hline Group investment & $\begin{array}{l}0.553^{* * * * 2 *} \\
(0.0813)\end{array}$ & $\begin{array}{l}0.577^{* * * *} \\
(0.0470)\end{array}$ & $\begin{array}{l}0.740 \\
(0.0395)\end{array}$ & $\begin{array}{l}0.807^{* * *} \\
(\mathbf{0 . 0 3 3 8})\end{array}$ & $\begin{array}{l}0.700^{* * *} \\
(0.0414)\end{array}$ \\
\hline Round & $\begin{array}{c}0.140 * \\
(0.0829)\end{array}$ & $\begin{array}{c}-0.0340 \\
(0.0712)\end{array}$ & $\begin{array}{c}0.225^{* *} \\
(0.0966)\end{array}$ & $\begin{array}{c}0.166 \\
(0.0830)\end{array}$ & $\begin{array}{c}0.137 \\
(0.0566)\end{array}$ \\
\hline Gini- coefficient Earnings (t-1) & $\begin{array}{l}-1.915 \\
(3.510)\end{array}$ & $\begin{array}{c}-3.986 \\
(4.085)\end{array}$ & $\begin{array}{c}2.623 \\
(2.102)\end{array}$ & $\begin{array}{c}3.448 \\
(2.364)\end{array}$ & $\begin{array}{c}-1.958 \\
(2.328)\end{array}$ \\
\hline Mean extraction except me (t-1) & $\begin{array}{c}-0.0705 \\
(0.0301)\end{array}$ & $\begin{array}{l}0.00602 \\
(0.0464)\end{array}$ & $\begin{array}{c}-0.101 \\
(0.0599)\end{array}$ & $\begin{array}{c}-0.0568^{*} \\
(0.0333)\end{array}$ & $\begin{array}{c}-0.0603 \\
(0.0445)\end{array}$ \\
\hline Extraction $(\mathrm{t}-1)$ & $\begin{array}{l}0.0487^{* *} \\
(0.0199)\end{array}$ & $\begin{array}{l}-0.0359 \\
(0.0516)\end{array}$ & $\begin{array}{c}0.0713 \\
(0.0371)\end{array}$ & $\begin{array}{c}0.0306 \\
(0.0267)\end{array}$ & $\begin{array}{l}0.0667^{* *} \\
(0.0330)\end{array}$ \\
\hline Interaction $\mathrm{C} \&$ treatment phase & $\begin{array}{c}1.325 \\
(1.140)\end{array}$ & $\begin{array}{l}-1.304^{*} \\
(0.767)\end{array}$ & $\begin{array}{l}-1.137 \\
(1.482)\end{array}$ & $\begin{array}{l}-3.765^{* *} \\
(1.514)\end{array}$ & $\begin{array}{l}4.461^{* * *} \\
(1.233)\end{array}$ \\
\hline Interaction TA \& treatment phase & $\begin{array}{c}-0.697 \\
(1.128)\end{array}$ & $\begin{array}{c}-0.120 \\
(1.454)\end{array}$ & $\begin{array}{c}2.050 \\
(1.524)\end{array}$ & $\begin{array}{c}1.663 \\
(2.931)\end{array}$ & $\begin{array}{l}2.638 \\
(1.289)\end{array}$ \\
\hline Interaction P \& treatment phase & $\begin{array}{c}-0.545 \\
(1.569)\end{array}$ & $\begin{array}{c}1.746 \\
(1.443)\end{array}$ & $\begin{array}{l}4.042^{* * *} \\
(1.493)\end{array}$ & $\begin{array}{l}2.311^{* *} \\
(1.091)\end{array}$ & $\begin{array}{c}0.613 \\
(1.576)\end{array}$ \\
\hline Interaction IC \& treatment phase & $\begin{array}{c}-4.434^{* *} \\
(1.900)\end{array}$ & $\begin{array}{l}-0.195 \\
(0.593)\end{array}$ & $\begin{array}{c}0.620 \\
(2.237)\end{array}$ & $\begin{array}{c}2.652^{*} \\
(1.578)\end{array}$ & $\begin{array}{c}0.905 \\
(0.911)\end{array}$ \\
\hline Received C treatment $(\mathrm{t}-1)$ & $\begin{array}{c}0.295 \\
(0.817)\end{array}$ & $\begin{array}{c}0.918 \\
(3.377)\end{array}$ & $\begin{array}{c}2.261^{*} \\
(1.215)\end{array}$ & $\begin{array}{l}2.185^{* * *} \\
(0.929)\end{array}$ & $\begin{array}{c}-3.815^{* *} \\
(1.799)\end{array}$ \\
\hline Received TA treatment (t-1) & $\begin{array}{l}5.266^{* * * *} \\
(1.393)\end{array}$ & $\begin{array}{c}1.797 \\
(3.944)\end{array}$ & $\begin{array}{c}-0.696 \\
(1.322)\end{array}$ & $\begin{array}{c}1.761 \\
(1.608)\end{array}$ & $\begin{array}{c}1.126 \\
(1.046)\end{array}$ \\
\hline Received $\mathrm{P}$ treatment $(\mathrm{t}-1)$ & $\begin{array}{c}-1.942^{* * *} \\
(0.717)\end{array}$ & $\begin{array}{c}0.459 \\
(1.117)\end{array}$ & $\begin{array}{c}-2.104^{* * *} \\
(0.804)\end{array}$ & $\begin{array}{c}-0.327 \\
(1.399)\end{array}$ & $\begin{array}{l}-0.449 \\
(1.581)\end{array}$ \\
\hline Initiated TA treatment $(\mathrm{t}-1)$ & $\begin{array}{l}-1.177 \\
(0.873)\end{array}$ & $\begin{array}{l}-0.199 \\
(0.953)\end{array}$ & $\begin{array}{l}-1.279 \\
(1.182)\end{array}$ & $\begin{array}{c}1.410 \\
(1.062)\end{array}$ & $\begin{array}{c}0.744 \\
(1.275)\end{array}$ \\
\hline Initiated $\mathrm{C}$ treatment $(\mathrm{t}-1)$ & $\begin{array}{c}-3.932^{* * *} \\
(1.495)\end{array}$ & $\begin{array}{l}-1.155 \\
(0.950)\end{array}$ & $\begin{array}{c}-2.201 \\
(1.437)\end{array}$ & $\begin{array}{l}-0.797 \\
(0.877)\end{array}$ & $\begin{array}{c}0.681 \\
(1.621)\end{array}$ \\
\hline Initiated $\mathrm{P}$ treatment $(\mathrm{t}-1)$ & -0.151 & -1.161 & -1.074 & $-1.767^{*}$ & -1.472 \\
\hline
\end{tabular}




\begin{tabular}{|c|c|c|c|c|c|}
\hline Constant & $\begin{array}{c}(0.865) \\
-7.017^{* * * *} \\
(\mathbf{2 . 5 2 8})\end{array}$ & $\begin{array}{l}(1.073) \\
-7.633^{*} \\
(\mathbf{4 . 2 8 4 )}\end{array}$ & $\begin{array}{c}(0.695) \\
-9.329^{* * *} \\
\mathbf{( 3 . 5 5 6 )}\end{array}$ & $\begin{array}{c}(0.914) \\
-\mathbf{2 1 . 7 4} \\
(\mathbf{2 . 8 8 * *} \\
\end{array}$ & $\begin{array}{l}(1.325) \\
-20.77^{* * *} \\
(\mathbf{3 . 0 7 1})\end{array}$ \\
\hline \multicolumn{6}{|l|}{ Random-effects Parameters } \\
\hline Village & $\begin{array}{c}0.0529 \\
(0.386)\end{array}$ & $\begin{array}{l}0.689^{* *} \\
(0.279)\end{array}$ & $\begin{array}{c}0.285 \\
(0.406)\end{array}$ & $\begin{array}{l}-1.087 \\
(4.728)\end{array}$ & $\begin{array}{c}0.241 \\
(0.249)\end{array}$ \\
\hline Group & $\begin{array}{l}-0.0172 \\
(0.559)\end{array}$ & $\begin{array}{l}0.660^{* * *} \\
(0.257)\end{array}$ & $\begin{array}{l}-17.40 \\
(81.92)\end{array}$ & $\begin{array}{l}-0.0601 \\
(0.727)\end{array}$ & $\begin{array}{c}-0.587 \\
(1.006)\end{array}$ \\
\hline Residual & $\begin{array}{l}1.631^{* * *} \\
(0.0952)\end{array}$ & $\begin{array}{l}1.484^{* * *} \\
(0.0946)\end{array}$ & $\begin{array}{l}1.567^{* * *} \\
(0.0777)\end{array}$ & $\begin{array}{l}1.529^{* * *} \\
(0.0431)\end{array}$ & $\begin{array}{l}1.620^{* * * *} \\
(0.0450)\end{array}$ \\
\hline No. of players & 32 & 32 & 32 & 32 & 32 \\
\hline No. of observations & 482 & 482 & 482 & 482 & 482 \\
\hline
\end{tabular}

Table A4.4. Mixed effects regression models explaining the total tokens invested and earned from water extraction by groups (coefficients with robust standard errors in parentheses; * $\mathrm{p}<$ $0.1, * * \mathrm{p}<0.05, * * * \mathrm{p}<0.01)$.

\begin{tabular}{|c|c|c|c|c|}
\hline & $\begin{array}{c}\text { Group } \\
\text { investment }\end{array}$ & $\begin{array}{c}\text { Group } \\
\text { investment }\end{array}$ & $\begin{array}{c}\text { Group } \\
\text { Extraction } \\
\text { (Tokens) }\end{array}$ & $\begin{array}{c}\text { Group } \\
\text { Extraction } \\
\text { (Tokens) }\end{array}$ \\
\hline & (Round 8-18) & (Round 2-18) & (Round 8-18) & (Round 2-18) \\
\hline$\sigma$ age & $\begin{array}{c}0.135^{*} \\
(0.0741)\end{array}$ & $\begin{array}{l}-0.458 \\
(0.371)\end{array}$ & $\begin{array}{l}-0.458 \\
(0.371)\end{array}$ & $\begin{array}{l}-0.265 \\
(0.398)\end{array}$ \\
\hline$\sigma$ size land holding & $\begin{array}{l}-0.0894 \\
(0.0870)\end{array}$ & $\begin{array}{l}-0.165 \\
(0.311)\end{array}$ & $\begin{array}{l}-0.165 \\
(0.311)\end{array}$ & $\begin{array}{l}-0.195 \\
(0.318)\end{array}$ \\
\hline$\sigma$ education level & $\begin{array}{l}0.0521 \\
(1.375)\end{array}$ & $\begin{array}{l}-1.276 \\
(3.716)\end{array}$ & $\begin{array}{l}-1.276 \\
(3.716)\end{array}$ & $\begin{array}{l}-1.278 \\
(4.045)\end{array}$ \\
\hline No. of casts in group & $\begin{array}{c}0.459 \\
(0.794)\end{array}$ & $\begin{array}{l}-0.865 \\
(3.093)\end{array}$ & $\begin{array}{l}-0.865 \\
(3.093)\end{array}$ & $\begin{array}{l}-0.409 \\
(2.616)\end{array}$ \\
\hline $\begin{array}{l}\text { Network density of } \\
\text { social relations }\end{array}$ & $\begin{array}{c}4.807 \\
(3.175)\end{array}$ & $\begin{array}{r}3.086 \\
(8.918) \\
\end{array}$ & $\begin{array}{c}3.086 \\
(8.918)\end{array}$ & $\begin{array}{c}2.021 \\
(8.670)\end{array}$ \\
\hline \multicolumn{5}{|c|}{ Village variables } \\
\hline No. of households & $\begin{array}{l}-0.00637 \\
(0.00445)\end{array}$ & $\begin{array}{l}-0.0028 \\
(0.0034)\end{array}$ & $\begin{array}{l}-0.0161 \\
(0.0137)\end{array}$ & $\begin{array}{l}-0.003 \\
(0.012)\end{array}$ \\
\hline $\begin{array}{l}\text { Head- or tail-end } \\
\text { location }\end{array}$ & $\begin{array}{l}-0.950 \\
(0.805)\end{array}$ & $\begin{array}{c}0.394 \\
(0.719)\end{array}$ & $\begin{array}{l}-1.665 \\
(1.984)\end{array}$ & $\begin{array}{c}0.436 \\
(1.986)\end{array}$ \\
\hline Distance to market & $\begin{array}{l}0.124^{* *} \\
(0.0587)\end{array}$ & $\begin{array}{c}0.152^{* *} \\
(0.0629)\end{array}$ & $\begin{array}{l}-0.255 \\
(0.204)\end{array}$ & $\begin{array}{l}-0.108 \\
(0.232)\end{array}$ \\
\hline $\begin{array}{l}\text { Frequency of water } \\
\text { disputes }\end{array}$ & $\begin{array}{l}0.690^{* *} \\
(0.296)\end{array}$ & $\begin{array}{c}-0.00150 \\
(0.293)\end{array}$ & $\begin{array}{c}2.487 \\
(1.556)\end{array}$ & $\begin{array}{c}0.935 \\
(1.634)\end{array}$ \\
\hline
\end{tabular}

Game variables 


\begin{tabular}{|c|c|c|c|c|}
\hline Round & $\begin{array}{c}0.112 \\
(0.121)\end{array}$ & $\begin{array}{l}0.816 \\
(0.369)\end{array}$ & $\begin{array}{l}0.623^{* * *} \\
(0.200)\end{array}$ & $\begin{array}{l}0.634^{* * *} \\
(0.160)\end{array}$ \\
\hline $\begin{array}{l}\text { Gini-coeff. Investment } \\
(\mathrm{t}-1)\end{array}$ & $\begin{array}{l}-14.64^{*} \\
(7.997)\end{array}$ & $\begin{array}{l}-20.83^{* *} \\
(9.810)\end{array}$ & $\begin{array}{l}-6.041 \\
(11.97)\end{array}$ & $\begin{array}{c}6.530 \\
(11.44)\end{array}$ \\
\hline Group investment & - & - & $\begin{array}{l}3.296 * * * \\
(0.153)\end{array}$ & $\begin{array}{c}3.424 * * * \\
(0.179)\end{array}$ \\
\hline $\begin{array}{l}\text { Gini-coeff. Extraction } \\
(\mathrm{t}-1)\end{array}$ & - & - & $\begin{array}{c}0.898 \\
(5.400)\end{array}$ & $\begin{array}{c}0.885 \\
(4.076)\end{array}$ \\
\hline $\begin{array}{l}\text { Gini-coeff. Earnings (t- } \\
\text { 1) }\end{array}$ & $\begin{array}{l}-18.28^{* * * *} \\
(7.084)\end{array}$ & $\begin{array}{l}-17.25 \\
(21.03)\end{array}$ & (2 & (2 \\
\hline $\begin{array}{l}\text { Interaction C \& } \\
\text { treatment phase }\end{array}$ & $\begin{array}{c}2.047 \\
(1.533)\end{array}$ & $\begin{array}{l}0.0754 \\
(1.796)\end{array}$ & $\begin{array}{c}8.888 \\
(5.565)\end{array}$ & $\begin{array}{l}-2.251 \\
(5.322)\end{array}$ \\
\hline $\begin{array}{l}\text { Interaction TA \& } \\
\text { treatment phase }\end{array}$ & $\begin{array}{c}2.156 \\
(1.754)\end{array}$ & $\begin{array}{l}-0.0712 \\
(1.594)\end{array}$ & $\begin{array}{c}6.386 \\
(6.213)\end{array}$ & $\begin{array}{l}-1.244 \\
(4.167)\end{array}$ \\
\hline $\begin{array}{l}\text { Interaction P \& } \\
\text { treatment phase }\end{array}$ & $\begin{array}{c}0.107 \\
(2.508)\end{array}$ & $\begin{array}{l}-1.447 \\
(2.299)\end{array}$ & $\begin{array}{l}-1.208 \\
(7.946)\end{array}$ & $\begin{array}{l}-9.033^{*} \\
(5.466)\end{array}$ \\
\hline $\begin{array}{l}\text { Interaction IC \& } \\
\text { treatment phase }\end{array}$ & - & $\begin{array}{l}-1.049 \\
(1.349)\end{array}$ & - & $\begin{array}{l}-5.456 \\
(4.526)\end{array}$ \\
\hline Constant & $\begin{array}{l}34.61^{* * *} \\
(2.340)\end{array}$ & $\begin{array}{l}35.40^{* * *} \\
(4.242)\end{array}$ & $\begin{array}{l}83.67^{* * *} \\
(10.46)\end{array}$ & $\begin{array}{l}84.38^{* * * *} \\
(12.18)\end{array}$ \\
\hline \multicolumn{5}{|c|}{ Random-effects Parameters } \\
\hline Village & $\begin{array}{l}-23.95 \\
(84.50)\end{array}$ & $\begin{array}{l}-15.98 \\
(66.2)\end{array}$ & $\begin{array}{l}-13.34^{* * * *} \\
(2.905)\end{array}$ & $\begin{array}{l}-15.50 \\
(228.1)\end{array}$ \\
\hline Group & & $\begin{array}{l}0.960^{* * *} \\
(0.378)\end{array}$ & $\begin{array}{l}2.178^{* * *} \\
(0.360)\end{array}$ & $\begin{array}{c}2.073 \\
(3.449)\end{array}$ \\
\hline Residual & $\begin{array}{l}1.909^{* * *} \\
(0.0579)\end{array}$ & $\begin{array}{l}\mathbf{1 . 8 2 6}^{* * *} \\
(\mathbf{0 . 0 5 4 8 )}\end{array}$ & $\begin{array}{l}2.453^{* * *} \\
(0.0457)\end{array}$ & $\begin{array}{l}2.479^{* * *} \\
(\mathbf{0 . 0 2 9 7})\end{array}$ \\
\hline No. of Groups & 32 & 32 & 32 & 32 \\
\hline No. of observations & 290 & 482 & 290 & 482 \\
\hline
\end{tabular}

Table A4.5. Tobit models explaining the decision to initiate treatment against other players (coefficients with standard errors in parentheses; $* \mathrm{p}<0.1, * * \mathrm{p}<0.05, * * * \mathrm{p}<0.01$ ).

\section{(1) (2)}

frequency how often player frequency how often player initiated treatment received treatment

$\begin{array}{lcc}\text { Position number } & 0.589 & \mathbf{- 0 . 7 6 7 ^ { * * * }} \\ \text { Education level } & (0.306) & \mathbf{( 0 . 1 8 0 )} \\ & 0.588^{*} & -0.0785 \\ \text { Age } & (0.253) & (0.177) \\ & 0.0170 & -0.0158 \\ \text { Size of Land holdings } & (0.0248) & (0.0122) \\ & 0.0150 & 0.00330 \\ & (0.0139) & (0.0128)\end{array}$




\begin{tabular}{lcc} 
Member dominant Baradari & -1.223 & -0.219 \\
Degree kinship & $(1.078)$ & $(0.548)$ \\
& 0.401 & 0.127 \\
Constant & $(0.275)$ & $(0.194)$ \\
& $\mathbf{- 5 . 3 9 3}^{* * * *}$ & $\mathbf{3 . 2 9 5}$ \\
\hline Sigma & $(\mathbf{1 . 5 8 3 )}$ & $\mathbf{( 0 . 7 6 8 )}$ \\
Constant & $\mathbf{3 . 0 5 1}^{* * *}$ & $\mathbf{1 . 9 5 7}^{* * *}$ \\
& $\mathbf{( 0 . 4 5 7 )}$ & $\mathbf{( 0 . 2 3 4 )}$ \\
\hline Observations & 160 & 160 \\
\hline
\end{tabular}




\section{APPENDIX 5}

Gini-coefficients for investment and extraction

Figure A5.1. Average group Gini-coefficient for investment and extraction over experiment rounds

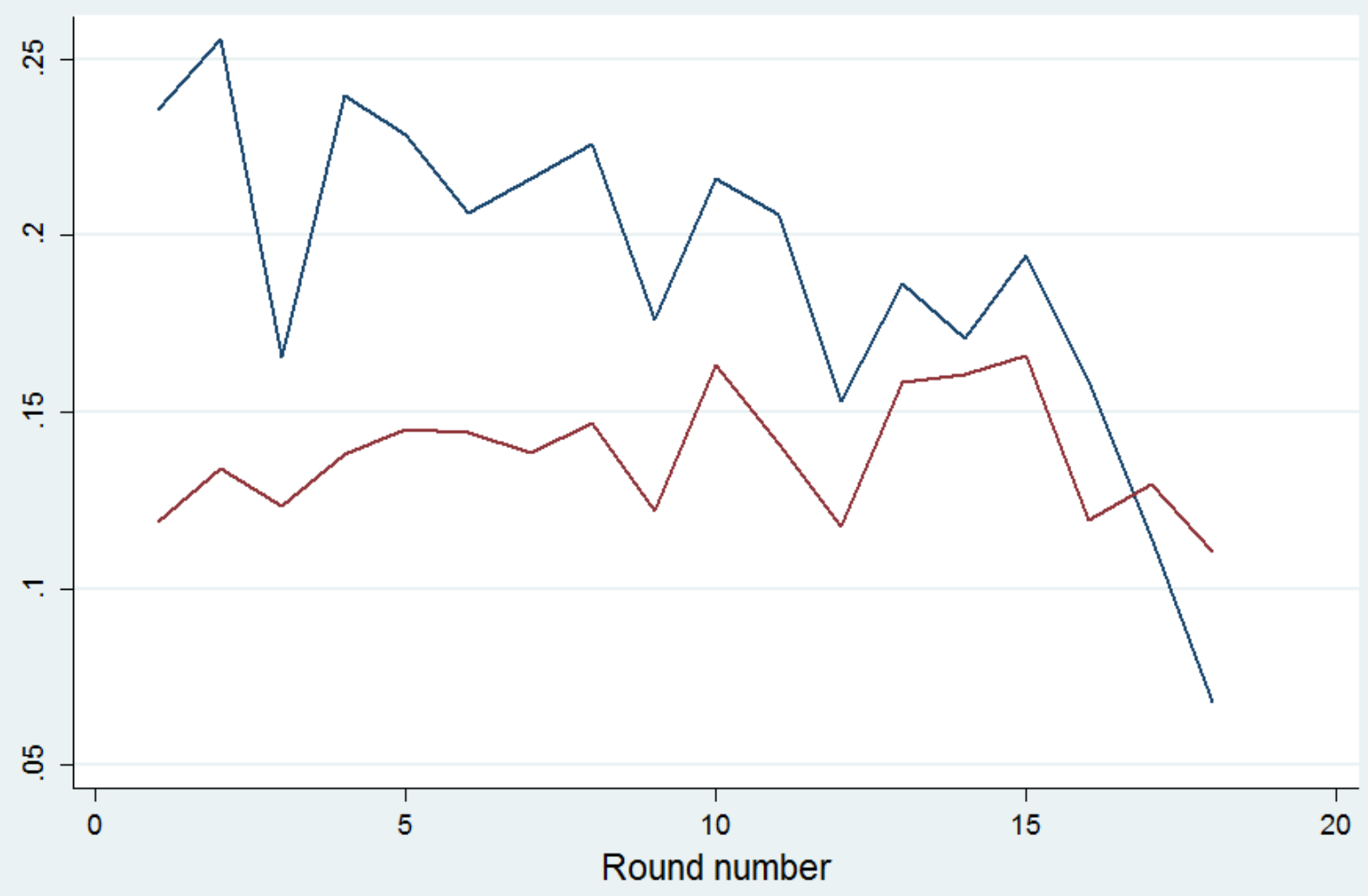

Table A5.1. Mixed effects regression models explaining Gini-coefficients of extraction (coefficients with standard errors in parentheses; ${ }^{*} \mathrm{p}<0.1,{ }^{* *} \mathrm{p}<0.05$, ${ }^{* * *} \mathrm{p}<0.01$ ).

\begin{tabular}{|c|c|c|c|}
\hline & Gini-coeff. investment & Gini-coeff. earnings & Gini-coeff. extraction \\
\hline \multicolumn{4}{|l|}{ Group variables } \\
\hline \multirow{2}{*}{$\sigma$ age } & 0.000897 & $0.00424^{* *}$ & 0.00250 \\
\hline & $(0.00137)$ & $(0.00166)$ & $(0.00309)$ \\
\hline \multirow{2}{*}{$\sigma$ size land holding } & $0.00336^{* * * *}$ & $0.00188^{*}$ & 0.00205 \\
\hline & $(0.000871)$ & $(0.00107)$ & $(0.00125)$ \\
\hline \multirow{2}{*}{$\sigma$ education level } & -0.0131 & $-0.0315^{* *}$ & -0.00214 \\
\hline & $(0.0115)$ & $(0.0146)$ & $(0.0231)$ \\
\hline \multirow{2}{*}{ No. of casts in group } & -0.00131 & 0.00116 & 0.0207 \\
\hline & $(0.0147)$ & $(0.0147)$ & $(0.0171)$ \\
\hline Network density of & $-0.0806^{* * * *}$ & $0.0485^{*}$ & 0.0489 \\
\hline social relations & $(0.0306)$ & $(0.0279)$ & $(0.0387)$ \\
\hline
\end{tabular}

Village variables 


\begin{tabular}{|c|c|c|c|}
\hline No. of households & $\begin{array}{c}0.000112^{*} \\
(0.0000667)\end{array}$ & $\begin{array}{l}0.000176^{* * * *} \\
(0.0000484)\end{array}$ & $\begin{array}{l}0.000225 \\
(0.000101)\end{array}$ \\
\hline $\begin{array}{l}\text { Head- or tail-end } \\
\text { location }\end{array}$ & $\begin{array}{c}-0.0177 \\
(0.0173)\end{array}$ & $\begin{array}{c}-0.0620 \\
(0.0159)\end{array}$ & $\begin{array}{c}-0.0511^{* * * *} \\
(0.0181)\end{array}$ \\
\hline Distance to market & $\begin{array}{l}-0.000632 \\
(0.00176)\end{array}$ & $\begin{array}{l}0.000812 \\
(0.00163)\end{array}$ & $\begin{array}{c}0.00210 \\
(0.00140)\end{array}$ \\
\hline $\begin{array}{l}\text { Frequency of water } \\
\text { disputes }\end{array}$ & $\begin{array}{l}0.000294 \\
(0.00869)\end{array}$ & $\begin{array}{c}0.0111 \\
(0.00980)\end{array}$ & $\begin{array}{l}0.00465 \\
(0.0118)\end{array}$ \\
\hline \multicolumn{4}{|l|}{ Game variables } \\
\hline Round number & $\begin{array}{c}0.00144 \\
(0.00151)\end{array}$ & $\begin{array}{l}-0.00291 * \\
(0.00168)\end{array}$ & $\begin{array}{c}-\mathbf{0 . 0 0 5 5 5} * * \\
(0.00272)\end{array}$ \\
\hline $\begin{array}{l}\text { Interaction C \& } \\
\text { treatment phase }\end{array}$ & $\begin{array}{l}-0.0182 \\
(0.0320)\end{array}$ & $\begin{array}{l}-0.0549 \\
(0.0345)\end{array}$ & $\begin{array}{l}-0.0354 \\
(0.0400)\end{array}$ \\
\hline Interaction TA \& & -0.0215 & 0.0113 & 0.0146 \\
\hline treatment phase & $(0.0213)$ & $(0.0198)$ & $(0.0453)$ \\
\hline Interaction P \& & 0.0271 & 0.00883 & 0.0232 \\
\hline treatment phase & $(0.0408)$ & $(0.0328)$ & $(0.0466)$ \\
\hline Interaction IC \& & 0.00517 & 0.00610 & 0.0366 \\
\hline treatment phase & $(0.0241)$ & $(0.0309)$ & $(0.0617)$ \\
\hline constant & $\begin{array}{c}0.117 \\
(0.0775)\end{array}$ & $\begin{array}{c}0.125^{* *} \\
(0.0543)\end{array}$ & $\begin{array}{c}0.0520 \\
(0.0736)\end{array}$ \\
\hline \multicolumn{4}{|c|}{ Random-effects Parameters } \\
\hline Village & $\begin{array}{c}-4.243^{* * * *} \\
(0.559)\end{array}$ & $\begin{array}{c}-4.258^{* * * *} \\
(0.663)\end{array}$ & $\begin{array}{l}-4.526^{* * *} \\
(2.144)\end{array}$ \\
\hline Residual & $\begin{array}{l}-2.330 \\
(0.0921)\end{array}$ & $\begin{array}{l}-2.193^{* * *} \\
(0.0536)\end{array}$ & $\begin{array}{l}-1.775^{* * *} \\
(0.0735)\end{array}$ \\
\hline No. of Groups & 32 & 32 & 32 \\
\hline Nof Observations & 514 & 514 & 514 \\
\hline
\end{tabular}




\section{Appendix 6}

Total amount of water wasted in baseline and treatment rounds

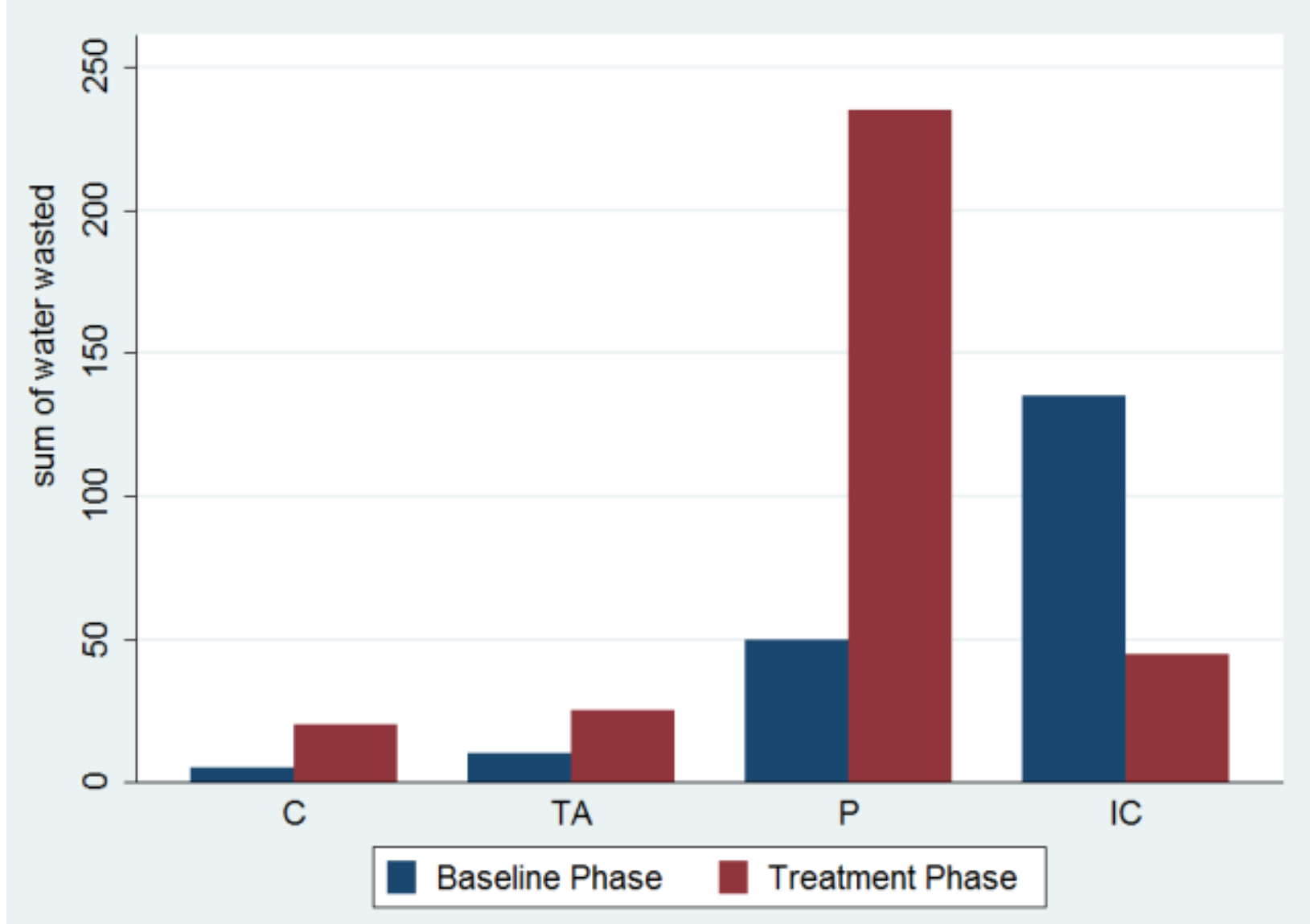

